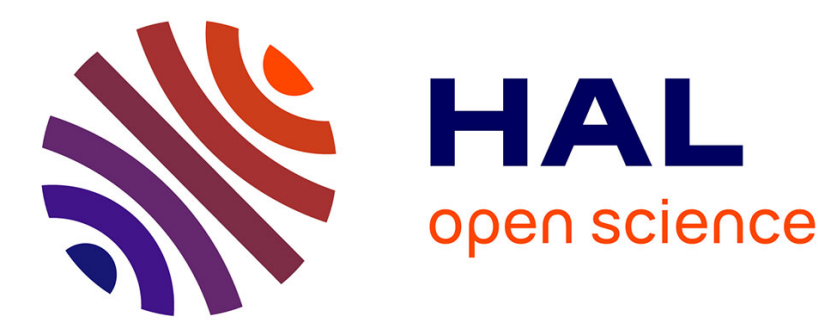

\title{
Component deficits of visual neglect: "magnetic" attraction of attention vs. impaired spatial working memory
}

Monica N Toba, Marco Rabuffetti, Christophe Duret, Pascale Pradat-Diehl, Guido Gainotti, Paolo Bartolomeo

\section{To cite this version:}

Monica N Toba, Marco Rabuffetti, Christophe Duret, Pascale Pradat-Diehl, Guido Gainotti, et al.. Component deficits of visual neglect: "magnetic" attraction of attention vs. impaired spatial working memory. Neuropsychologia, 2018, 109, pp.52-62. 10.1016/j.neuropsychologia.2017.11.034 . hal02171347

\section{HAL Id: hal-02171347 \\ https://hal.sorbonne-universite.fr/hal-02171347}

Submitted on 2 Jul 2019

HAL is a multi-disciplinary open access archive for the deposit and dissemination of scientific research documents, whether they are published or not. The documents may come from teaching and research institutions in France or abroad, or from public or private research centers.
L'archive ouverte pluridisciplinaire HAL, est destinée au dépôt et à la diffusion de documents scientifiques de niveau recherche, publiés ou non, émanant des établissements d'enseignement et de recherche français ou étrangers, des laboratoires publics ou privés. 


\section{Component deficits of visual neglect: "magnetic" attraction of attention vs. impaired}

\section{spatial working memory}

Monica N. Toba ${ }^{1,2}$, Marco Rabuffetti ${ }^{3}$, Christophe Duret ${ }^{4}$, Pascale Pradat-Diehl ${ }^{5,6}$, Guido

$$
\text { Gainotti }^{7,8} \text {, Paolo Bartolomeo }{ }^{1}
$$

${ }^{1}$ Inserm U 1127, CNRS UMR 7225, Sorbonne Universités, UPMC Univ Paris 06 UMR S 1127, Institut du Cerveau et de la Moelle épinière, ICM, F-75013, Paris, France

${ }^{2}$ Laboratory of Functional Neurosciences (EA 4559), University Hospital of Amiens and University of Picardy Jules Verne, Amiens, France.

${ }^{3}$ Department of Biomedical Technology, IRCCS Don Carlo Gnocchi Foundation Milan, Italy.

${ }^{4}$ Service de Neurorééducation, Clinique Les Trois Soleils, Boissise le Roi, France.

5 AP-HP, HxU Pitié-Salpêtrière-Charles-Foix, Service de Médecine Physique et de Réadaptation, Paris, France.

${ }^{6}$ GRC-UPMC n ${ }^{\circ} 18-$ Handicap cognitif et réadaptation.

${ }^{7}$ Institute of Neurology of the Università Cattolica del Sacro Cuore of Rome, Italy.

${ }^{8}$ IRCCS Fondazione Santa Lucia, Department of Clinical and Behavioral Neurology, Rome, Italy.

Corresponding author:

Dr. Monica N. Toba, PhD

University of Picardy Jules Verne, Laboratory of Functional Neurosciences (EA 4559), Amiens, France

CHU Amiens Picardie - Site Sud

Centre Universitaire de Recherche en Santé (Bâtiment CURS)

Avenue René Laënnec, 80054 Amiens Cedex 1, France

E-mail: monica.n.toba@gmail.com 


\section{Abstract}

Visual neglect is a disabling consequence of right hemisphere damage, whereby patients fail to detect left-sided objects. Its precise mechanisms are debated, but there is some consensus that distinct component deficits may variously associate and interact in different patients. Here we used a touch-screen based procedure to study two putative component deficits of neglect, rightward "magnetic" attraction of attention and impaired spatial working memory, in a group of 47 right brain-damaged patients, of whom 33 had signs of left neglect. Patients performed a visual search task on three distinct conditions, whereby touched targets could (1) be tagged, (2) disappear or (3) show no change. Magnetic attraction of attention was defined as more left neglect on the tag condition than on the disappear condition, where right-sided disappeared targets could not capture patients' attention. Impaired spatial working memory should instead produce more neglect on the no change condition, where no external cue indicated that a target had already been explored, than on the tag condition. Using a specifically developed analysis algorithm, we identified significant differences of performance between the critical conditions. Neglect patients as a group performed better on the disappear condition than on the no change condition and also better in the tag condition comparing with the no change condition. No difference was found between the tag condition and the disappear condition. Some of our neglect patients had dissociated patterns of performance, with predominant magnetic attraction or impaired spatial working memory. Anatomical results issued from both grey matter analysis and fiber tracking were consistent with the typical patterns of fronto-parietal and occipito-frontal disconnection in neglect, but did not identify lesional patterns specifically associated with one or another deficit, thus suggesting the possible co-localization of attentional and 
working memory processes in fronto-parietal networks. These findings give support to the hypothesis of the co-occurrence of distinct cognitive deficits in visual neglect and stress the necessity of multi-component models of visuospatial disorders.

Keywords: neglect, magnetic attraction of attention, working memory, clinical anatomical correlations, tractography, stroke 


\section{Introduction}

Visual neglect is a dramatic neurological condition resulting from right hemisphere lesions, whereby patients fail to detect and respond to left-sided objects (Bartolomeo, 2007; Halligan \& Bartolomeo, 2012; Heilman, Watson, \& Valenstein, 1993; Mesulam, 1981; Parton, Malhotra, \& Husain, 2004). When asked to cross out targets scattered on a sheet, neglect patients typically restrict their exploration to the right part of the sheet and omit cancelling left-sided targets (Albert, 1973). The precise mechanisms leading to neglect behavior are object of debate since almost a century, but some consensus is now emerging that distinct component deficits of neglect may variously dissociate in some patients (Barbieri \& De Renzi, 1989; Binder, Marshall, Lazar, Benjamin, \& Mohr, 1992; Charras et al., 2012; Heilman, Watson, \& Valenstein, 2002; Mesulam, 1985; Mesulam, 2000; Vallar, 1998), or combine and interact in others (Bartolomeo, 2007; Coulthard, Parton, \& Husain, 2007; Gainotti, D'Erme, \& Bartolomeo, 1991; Karnath, 1988). As a consequence, the focus of research is now shifting to the identification of these component deficits, to the study of their modes of interactions and the exploration of their anatomical bases. Clinically, patients with left neglect often demonstrate a striking immediate capture of attention from ipsilesional, right-sided items as soon as a visual scene unfolds (De Renzi, Gentilini, Faglioni, \& Barbieri, 1989). For example, when patients' visual fields are tested by using the confrontation method, as soon as the examiner unfolds his/her arms in the patients' visual fields, patients may immediately lose fixation and shift their gaze towards the right-sided hand, as if ipsilesional stimuli exerted a sort of "magnetic" attraction (MA) on their attention and gaze (Gainotti et al., 1991). More generally, patients tend to produce inappropriate right-directed saccades when they should look at left-sided targets (Bourgeois et al., 2015). Consistent with these observations, patients may show reduced neglect in cancellation tasks when they erase targets rather than 
drawing over them (Mark, Kooistra, \& Heilman, 1988), presumably because removed rightsided targets have no possibility of capturing patients' attention, thus allowing patients to better explore the left portion of the sheet. The attentional capture exerted by right-sided items is typically followed by an impaired disengagement of attention from these items (Posner, Walker, Friedrich, \& Rafal, 1984; Rastelli, Funes, Lupiáñez, Duret, \& Bartolomeo, 2008). However, other component deficits may participate to impaired exploration in neglect. For example, Husain and co-workers (Husain et al., 2001; Malhotra et al., 2005; Wojciulik, Husain, Clarke, \& Driver, 2001; Wojciulik, Rorden, Clarke, Husain, \& Driver, 2004); Parton et al. (2006) suggested that signs of left neglect may be exacerbated by a nonlateralized deficit of spatial working memory (SWM), which would impair patients' ability to keep track of spatial locations (see also (D'Erme \& Bartolomeo, 1997; Kristjansson \& Vuilleumier, 2010). According to other authors (Pisella \& Mattingley, 2004), the SWM deficit also implies an impairment of visual remapping, with deficits in components such as storage, refreshment and re-localization of the elements of the visual scene. The visual remapping would thus be important to create constantly updated representations of stimulus location. Moreover, in cancellation tests, impaired SWM would cause patients to revisit previously detected targets and to treat them as if they had not been seen before. Consistent with this hypothesis, patients' neglect in cancellation tasks increased when targets did not change their appearance after having been touched (Husain et al., 2001; Wojciulik et al., 2001), a condition particularly taxing for SWM because there is no external cue indicating that a target has already been explored. Thus, evidence from distinct modified versions of cancellation tasks suggests the participation of both MA and impaired SWM in neglect patients' impaired spatial exploration. Such a clinical association does not, however, imply that these deficits always co-occur, nor that that they result from lesion to the same brain 
regions. It is, moreover, unknown what is the relative weight of MA and impaired SWM in shaping neglect behavior. Neuroimaging evidence suggests a co-localization of attentional and working memory processes in fronto-parietal networks (Awh \& Jonides, 2001); as a consequence, the relative deficits should systematically co-occur in patients with frontoparietal dysfunction (Bartolomeo, 2006b; Bartolomeo, Thiebaut de Schotten, \& Doricchi, 2007; Verdon, Schwartz, Lovblad, Hauert, \& Vuilleumier, 2010). Beyond their obvious interest for our knowledge of the brain mechanisms of spatial attention and spatial working memory, these questions have evident clinical implications for patients' management. Rehabilitation strategies (Halligan \& Bartolomeo, 2012) and emerging medical treatments (Gorgoraptis et al., 2012) are likely to show differences in effectiveness in different patients suffering from distinct deficits. Unfortunately, the methods hitherto used to assess MA or impaired SWM do not permit to dissect the relative contribution of these two putative deficits to neglect behavior. In the present study, we developed a computerized exploration task on a touch screen, which allowed us to separately assess these two deficits in a sample of patients with right hemisphere damage. In 3 different conditions, the targets touched by the patients could (1) be tagged by a change in color; (2) disappear; (3) show no change. SWM deficits should especially impair patients' performance on the no change condition, because there is no cue as to which targets have already been touched (Wojciulik et al., 2001; Wojciulik et al., 2004). On the other hand, performance of patients with MA and disengagement deficit should improve on the disappear condition, where no visible, attention-capturing right-sided targets remain on the screen after having being touched, thus decreasing left-sided omissions (Mark et al., 1988). 


\section{Methods}

\section{Participants}

All subjects gave written consent according to the Declaration of Helsinki. The study was approved by the Ile-de-France I research ethics committee. A total of 47 patients who had suffered a first episode of cerebro-vascular event in the right hemisphere participated in the study. All patients underwent a paper-and-pencil battery for diagnosis of neglect (see Table 1) (Azouvi et al., 2002). Thirty-three patients showed signs of left visual neglect on at least one test (mean age 64.03 years, range $39-85$ years, 12 females; mean time of testing since stroke onset 146.24 days); the remaining 14 patients (mean age 59.83 years, range 32-71 years, 7 females, mean time of testing since stroke onset 262.6 days) did not show any signs of neglect and were considered as brain-damaged controls. Thirteen of the neglect patients had left-sided visual field defects on confrontation test. The remaining 20 neglect patients had no visual field defects.

\section{Behavioral task}

The task was implemented on a 15'4" portable PC screen covered with a transparent touch screen (KTMT KEYTEC, INC, USA). Thirty-five empty white circles ( $2.81 \mathrm{~cm}$ diameter) were scattered pseudo-randomly on a black background. Participants were instructed to touch all the circles once with their index finger, in free vision (Figure 1). Participants' responses were collected in real-time by means of ad-hoc software (meyeParadigm, http://www.eyebrain.com/). In the three different conditions which characterized the test, as soon as a circle was touched, it (1) remained unchanged (No change condition); (2) became a more salient white-filled disk (Tag condition); (3) vanished (Disappear condition). The order of 
administration of the three conditions was counter-balanced among participants. Practice trials were proposed to participants in order for them to get acquainted with the task, the nature of the system feedbacks, the actions on the detected targets, and the instruction of touching each target only once. The system recognized any finger contact with a target and, besides producing the real-time effect, recorded in a log file the target position coordinates and the time of occurrence of the touching.

The main variable of interest was the pattern of exploration of the display in the three conditions. To this end, we assessed the sequence of touches on targets, as defined by their horizontal position on the $\mathrm{X}$ axis of the display (in pixels), with the center set to 0 . Left-sided targets received negative $X$ values, right-sided targets had positive $X$ values. The time latency in seconds (L) between two target detections was also computed. When patients touched repeatedly and consecutively the same target, only the timing of the first touch was considered. These parameters were computed for all the touched targets, for each participant and experimental condition. A latency-weighted average position was defined following a previously proposed procedure (Rabuffetti et al., 2012), derived from "center of mass" indexes proposed by Binder et al. (1992), Gainotti, Perri \& Cappa (2002), and Rorden \& Karnath (2010). The score is based on the position on the screen of the set of detected targets, with $x_{i}$ being the horizontal coordinate of the $i^{\text {th }}$ target and $L_{i}$ the associated detection latency. Larger scores mean more rightward bias (i.e., left neglect) in visual search. The latency-weighted average position along the horizontal $(X)$ coordinate was defined as (equation 1):

$$
\bar{x}_{w}=\frac{\sum w_{i} x_{i}}{\sum w_{i}}
$$


where the weight $w$ was defined on the basis of the latency of response (L) as (equation 2):

$$
w_{i}=\frac{1}{1+L_{i}}
$$

In practice, longer latencies decrease the weight of the detected targets, whose theoretical range goes from 0 (infinite latency) to 1 (zero latency). As an example, Figure 2 presents the graphical outcome of such a procedure applied to the performance of an individual patient.

The difference in performance between the baseline condition (tag condition) and the two other conditions (disappear and no change conditions) is quantified by the difference of the respective weighted average position of detected targets. Therefore two betweenconditions differential indexes can be defined as follows:

1) $\left(X_{\text {Disappear }}-X_{T a g}\right)$ was the difference between the average position of detected targets on the disappear condition and the average position of detected targets for the tag condition (baseline). Thus, negative values of $\left(\mathrm{X}_{\text {Disappear }}-\mathrm{X}_{\mathrm{Tag}}\right)$ indicated more neglect with tagged targets than with disappearing targets, which were unable to capture attention after the touch. This pattern of performance thus suggests an important contribution of MA.

2) $\left(X_{\text {NoChange }}-X_{T a g}\right)$ was the difference between the weighted average position of the detected targets on the no change condition and the average position of detected targets on the tag condition (baseline). Thus, positive values of $\left(\mathrm{X}_{\text {NoChange }}-\mathrm{X}_{\text {Tag }}\right)$ indicated more left neglect with unchanging targets than with tagged targets, consistent with a SWM deficit. 
Note that the present analysis only works if patients started their exploration from the right extremity of the display, as it is typically the case with right brain-damaged patients (Azouvi et al., 2002; Bartolomeo, 1997; Bartolomeo, D'Erme, \& Gainotti, 1994; Gainotti et al., 1991). However, patients may not invariably use this exploratory strategy. Thus, we thoroughly examined individual patients' performance, and identified a few cases of paradoxical patterns of exploration.

To summarize, we operationalized MA as the patient's tendency to start exploration from the right extremity of the display, with a substantial number of left omissions on the tag and no change conditions and an improvement in the disappear condition, where detected right-sided targets do not remain on the screen to capture the patient's attention (Mark et al., 1988). On the other hand, SWM impairment should manifest itself as increased left-sided omissions in the no change condition, where the patient has no direct feedback indicating that a target has already been explored (Husain et al., 2001).

\section{Neuroimaging acquisition}

Images were obtained on a 3T GE scanner with a standard head coil for signal reception located at the Hôpital de la Pitié Salpêtrière in Paris, France. Twenty-seven neglect patients with signs of left visual neglect had MRI scans including high resolution whole brain 3D standard T1-weighted anatomical images $(R T=7164 \mathrm{~ms} ; \mathrm{TE}=3124 \mathrm{~ms}$; inversion time = 380 $\mathrm{ms}$; acquisition matrix size $=[0,288,256,0]$; slice thickness $=1.2 \mathrm{~mm})$. For four patients, no images were available, and for two patients we could only acquire a CT scan. MRI acquisitions of several patients also included a diffusion-tensor sequence performed along 50 independent directions with a $\mathrm{b}$ value of $1000 \mathrm{~s} / \mathrm{mm}^{2}$. Imaging parameters were as follows: $R T=14$ s; TE = 75.8 ms; acquisition matrix = $[128,0,0,128]$; slice thickness = $3 \mathrm{~mm}$; 
acquisition time $=13 \mathrm{~min}$. Diffusion-tensor imaging allows the reconstruction in vivo of the white matter bundles and permits a consistent analysis of the white matter parameters, such as fractional anisotropy (FA). The FA measures the unequal, anisotropic diffusion of water in brain tissue (Basser, Mattiello, \& LeBihan, 1994) and is related to the presence of oriented structures (Le Bihan et al., 2001). Values near to 1 indicate that water molecules in a voxel are diffusing nearly entirely along one particular axis, whereas values approaching 0 indicate nearly equal diffusion in all directions. As a result, FA values tend to decrease in damaged fibers.

\section{Lesion mapping}

Brain lesions in stroke patients were plotted using MRIcro software (http://www.cabiatl.com/mricro/mricro/index.html) and a graphics tablet (WACOM Intuos A6). Lesion masks were firstly delineated on the original 3D images. Images were then normalized to a standard brain template (Brett, Leff, Rorden, \& Ashburner, 2001) using Statistical Parametric Mapping (http://www.fil.ion.ucl.ac.uk/spm/software/spm/) running under Matlab. Lesions were then segmented on normalized images and regions of interest (ROI) thus obtained were used in the subsequent analysis in MRIcron software (http://www.cabiatl.com/mricro/mricron/index.html) for conventional lesion density plots.

\section{Diffusion data processing and tractography procedures}

During the preprocessing of diffusion-weighted data, eddy current induced distortions were removed by using FSL software (http://www.fmrib.ox.ac.uk/fsl/). The estimation of the diffusion tensors was computed with Diffusion Toolkit software version 0.4.2 
(http://trackvis.org/dtk/). Using standard computational algorithm (Basser \& Pierpaoli, 1996), fractional anisotropy (FA) was calculated in the native space. FA threshold was set to 0.2 to exclude most of the voxels with high uncertainty and thus reduce the artifactual reconstruction. The critical angle threshold for stopping tracking in case the algorithm encountered a sharp turn in the fibers direction was fixated at $45^{\circ}$. A deterministic protocol of the interpolated streamline algorithm type was used. The tracking step was of $0.5 \mathrm{~mm}$. White matter tractography was performed using the Trackvis software version 0.4.2 (http://trackvis.org/dtk). Regions of interest (ROIs) were defined in order to be used as the starting points of the tracking process and were manually drawn on FA maps on places considered 'obligatory passages' along each white matter tract, as previously described (Catani, Howard, Pajevic, \& Jones, 2002; Catani, Jones, \& ffytche, 2005; Catani \& Thiebaut de Schotten, 2008; Thiebaut de Schotten et al., 2011; Thiebaut de Schotten et al., 2008). We performed single in vivo dissections of association pathways previously described as being involved in neglect behavior: the superior longitudinal fasciculus (SLF), the inferior frontooccipital fasciculus (IFOF) and the inferior longitudinal fasciculus (ILF). All ROls were demarcated on the native space. To ensure consistency in tracts values reported, all the white matter bundles were extracted by the same person.

Results

\section{Behavioral results}

Figure 3 shows the average latency-weighted scores for patients with or without signs of left neglect for each experimental condition. 
We computed an ANOVA with the latency-weighted average score as dependent variable, and the following factors: the patient group (two levels: neglect patients, non-neglect patients), and the task conditions (three levels: tag, disappear, no change). Only the main effect of the group $[F(1,45)=4,11 p<.04]$ and the interaction between group and experimental condition $[F(2,90)=3.59 p<.03]$ reached significance. Newman-Keuls post-hoc tests revealed that the interaction resulted from neglect patients performing worse on the no change condition than on the tag condition $(p<.01)$, and worse on the no change condition than on the disappear condition $(p<.008)$. There was no significant difference in performance between the tag condition and the disappear condition $(p>0.39)$.

To identify neglect patients demonstrating dissociations of performance between MA and SWM deficit, we established cutoff values based on the performance of the non-neglect group ( $\mathrm{N}=14$ ), who by definition did not show any such dissociation (see Figure 4). In particular, we identified the two values at each extremity of the distribution of the differential index, with a conservative p-value of 0.01 (in order to minimize type I classification errors) (Crawford, Garthwaite, \& Porter, 2010). Based on these indexes, we built a scatterplot graph with each patient's performance occupying a specific location (Figure 4). The latency-weighted average position allowed us to take into account response time asymmetries between the right side and the left side of the screen and thus to identify patients presenting slower responses to left-sided items compared with right-sided items (probably as a consequence of a partial compensation of their left neglect) such as patient P2 (see below, Figure S2C).

Nineteen neglect patients out of 33 did not show any differences in the differential indexes (i.e. their differential indexes were both inside the interval delimited by the cut-off values), 
thus demonstrating comparable performance on the three conditions. Four other patients had signs of predominant MA. However, perusal of individual performance (Figure S1) revealed that only two of these patients (P6 and P25) presented a consistent MA pattern, because they started exploration from the right extremity of the display and touched more items when they disappeared, and therefore ceased to capture patients' attention. The two remaining patients (P22 and P34) presented a paradoxical behavior with right-sided omissions in the disappear condition and a starting point on the left side, contrary to the definition of MA.

The classification algorithm assigned eight patients to the SWM deficit group (Figure S2A-B). Of these, P13, P20, P23, P28 and P31 presented a relatively consistent pattern suggesting a SWM deficit, with left omissions on the no change condition and normal or near-normal performance on the other conditions. Patients P13, P20 and P28 (Fig. S2A) sometimes started their exploration from the left side. This occurrence necessarily indicates the absence of MA. P23 and P31 (Fig. S2A) started their exploration from the right but their patterns of results were similar to those of P13, P20 and P28, consistent with the presence of a SWM impairment (without MA), probably in the context of a rehabilitated neglect. Patients P4, P8 and P27 started their exploration from the right side of the display. These patients had severe neglect on all conditions, with only marginal worsening of performance on the no change condition and starting points on the right side of the display. Although these three patients were assigned to the SWM group by our algorithm, their right-sided starting point suggests a contribution of MA.

The two remaining patients had unpredicted patterns of performance, with P2 showing an isolated improvement on the disappear condition, and P24 an isolated 
worsening on the same condition (Figure S2C), perhaps resulting from fluctuations in alertness during task performance.

\section{Neuroimaging study}

The overlay plot provided in Figure 5 shows the overall distribution of damaged areas [z coordinates from -26 to 37 in MNI (Montreal Neurological Institute) space] in the analyzed sample of unilateral neglect patients $(\mathrm{N}=27)$. This analysis highlighted the implication of the periventricular white matter above the insula. Based on the behavioral results, we selected for further analysis those patients who showed a consistent pattern of MA $(N=2)$ and of SWM deficit ( $N=5)$, as well as patients presenting a combined SWM impairment and MA deficit $(\mathrm{N}=3)$.

\section{General description of patients' lesional patterns}

Lesional patterns of patients presenting predominantly MA, SWM deficit and combined MA and SWM deficits are presented in Table 2 and Figure 6. Mean lesion volumes did not significantly differ between patients with a consistent SWM deficit $\left(n=5 ; m=124,813 \mathrm{~mm}^{3}\right.$ ) and patients without SWM deficits $\left(n=20 ; m=121,737 \mathrm{~mm}^{3}, t[23]=-0.04, p>0.9\right)$. In the predominant MA group, P25 presented a lesion concerning principally the lateral-dorsal nucleus of the thalamus, but also the temporal superior, middle and inferior and the temporo-occipital white matter (see Figure 6). For the other patient with predominant MA (P6), only a CT scan was available, with evidence of damage to the inferior parietal lobule. Lesional patterns of patients presenting a predominant SWM impairment (P13, P20, P23, P28 and P31) involved the inferior, middle and superior frontal gyri, the superior and inferior parietal cortex, the supramarginal and angular gyri, the postcentral gyrus, the superior and middle occipital gyri, the superior, middle and inferior temporal gyri, rolandic operculum, 
insula, putamen, caudate, thalamus, hippocampus and parahippocampal area (see Table 2 for details). Thus, grey matter lesional patterns did not clearly discriminate between MA and SWM deficits, with the possible exception of prefrontal damage, which was especially present in some patients with SWM deficit.

We had the opportunity to acquire diffusion-based images for P25 (predominant MA), and for P13, P20, P28 and P31 (predominant SWM deficit). In these patients, we performed an in vivo reconstruction of the white matter bundles previously reported as being important in the occurring of neglect signs (Doricchi, Thiebaut de Schotten, Tomaiuolo, \& Bartolomeo, 2008). To visually explore each pathway, white matter tracts were rendered as maps of FA values for both hemispheres on the high-resolution T1-weighted images. Figures S3 and S4 show the reconstruction and the FA values issued from the reconstruction of the superior longitudinal fasciculus (SLF), the inferior fronto-occipital fasciculus (IFOF) and the inferior longitudinal fasciculus (ILF) in the right and in the left hemisphere respectively. The SLF was well represented in both hemispheres but presented low FA values in the right hemisphere (especially in P31). IFOF and ILF were both disconnected in the right hemisphere in the P25 presenting a MA. Both IFOF and ILF were disconnected in two out of four analyzed patients (P13 and P20) presenting a SWM impairment. In one patient (P28) only the IFOF was disconnected, whereas in another patient (P31) all the bundles were represented. We should note that in this last patient the FA values of the SLF were very low (especially in the right hemisphere), compared with the other patients. Unfortunately, the DTI data did not allow us to perform a proper reconstruction of the corpus callosum. The available tractography data, admittedly obtained from a limited number of patients, do not permit to clearly disentangle disconnection patterns typical of MA or SWM deficits, perhaps also due to the fact that these deficits often co-occur in neglect. Except for one patient (P31), the 
IFOF was always disconnected in the right hemisphere, independent of the behavioral neglect pattern. On the other hand, the SLF was often preserved, but with lower FA in the right hemisphere than in the left hemisphere. ILF disconnection was always accompanied by disconnection of the adjacent IFOF, suggesting that ILF disconnection may not produce a crucial contribution to MA and SWM deficits.

\section{Discussion}

\section{Summary of results}

The present study reports on a detailed exploration of the occurrence of distinct component deficits of visual neglect, such as rightward magnetic attraction of attention and impaired spatial working memory, within a homogenous experimental setting. Previous evidence indicated that left neglect improves when right-sided targets disappear at the patients' touch, because they stop attracting patients' attention rightward (Mark et al., 1988; see also Bartolomeo et al., 2004). Neglect patients' performance as a group was indeed improved by target disappearance as compared to the no change condition, but not relative to the tag condition. The no change condition elicited the largest number of left-sided omissions. Other studies also found a worsening of left neglect when right-sided targets remained unchanged after detection, thus continuing to competing for patients' attention and taxing a putatively impaired short-term spatial memory (Husain et al., 2001; Malhotra et al., 2005; Parton et al., 2006; Wojciulik et al., 2001; Wojciulik et al., 2004). Obviously, to increase the number of leftlateralized omissions such a SWM deficit must interact with some sort of directional bias, such as MA. However, a double dissociation emerged in some individual patients, who showed a predominant influence of MA or SWM deficit. We were also able to perform an 
advanced anatomical analysis of the intra-hemispheric location of the lesion on some of the patients, taking into account both grey and white matter. However, this analysis did not disclose clearly different lesional patterns in the two conditions, perhaps because they tend to co-occur at least to some extent in neglect.

\section{Methodological considerations}

A novel feature of our behavioral paradigm was to put together conditions sensitive to the distinct deficits we aimed to explore, within a homogeneous experimental setting consisting of a touch-screen based visual search task. The only difference between the three experimental conditions was the feedback that patients received: touched targets could change color, show no change, or disappear. The use of a touch screen allowed us to increase the sensitivity of the task conditions to different forms of deficit, thanks to the detection of patients' accuracy, response time and pattern of exploration of the display. Weighting patients' accuracy with response times allowed us to uncover instances of spatial bias even when all the targets were detected, thus avoiding, or at least reducing, ceiling effects. Indeed, patients who learn to partially compensate for their left neglect typically display response time asymmetries, with slower responses to left-sided items (Bartolomeo, 1997, 2000; Rabuffetti et al., 2012). The present results extend this notion to visual search tasks. For example, patient P2 detected all the targets in the tag condition, but the latency was especially increased for left-sided stimuli. Thus, touch screen or tablet-based visual search tests such as the one we developed may identify cases of partial neglect compensation that would remain undetected with traditional paper and pencil tests (Bonato, 2012). This is a clinically relevant issue, because it would be risky for these patients to resume daily life activities requiring rapid responses to lateralized events, such as car 
driving. Another advantage of the present algorithm is that laterality is taken into account in a continuous way, in keeping with the gradient nature of neglect deficits, which do not follow a precise border between left and right hemispaces.

Also, the objective analysis algorithm we developed allowed us to establish cutoff scores based on the performance of control right brain-damaged patients without signs of neglect on paper-and-pencil tests, in order to answer the main question of the study, i.e. the relationships between magnetic attraction of attention and impaired spatial working memory. Our model assumes the typical performance of left neglect patients, with starting point on the right side and left-sided omissions. It obviously fails when right neglect occurs or when there are gaps in the cloud of detected targets, i.e. isolated neglected targets. Thus, perusal of individual performance in a few patients with apparently "pure" SWM deficit revealed that they started their exploration from right-sided targets, thus suggesting an MA contribution. As already noted, an additional directional component is logically necessary for a nonlateralized SWM impairment to contribute to left neglect signs. Despite these caveats, the model was generally effective in classifying patients, with only two patients showing unpredicted patterns of performance, perhaps as a result of random fluctuations in their level of alertness, which can interact with lateralized deficits in neglect (Chica et al., 2012; Robertson, Mattingley, Rorden, \& Driver, 1998).

Relation with other studies

While the present research was in progress, another study using similar methods on 18 right brain-damaged patients was published (Keller, Volkening, \& Garbacenkaite, 2015). The results replicated the observation of decreased neglect with disappearing targets (Mark et al., 1988), but not its worsening with no-change targets, contrary to previous evidence 
(Wojciulik et al., 2004) and to the present results. The no-change condition only increased perseverations of response. This discrepancy may result from differences in the experimental material. Whereas we used a relatively large $15^{\prime} 4^{\prime \prime}$ inches touch screen, Keller et al. (2015) employed an iPad, with its relatively small 10-inches display. The consequently limited scattering of targets in space made perhaps easier for patients to complete the task in the no-change condition, when there were no attention-capturing changes after each touch. Moreover, Keller et al. (2015) considered only overall omissions and perseverations, and did not analyze patients' response times and scan paths. The presence/absence of visual feedback, likely to exacerbate, respectively, MA and SWM deficits, has been reported to influence neglect patients' performance in contexts other than visual search tasks. For example, "blind" drawing, whereby patients produce drawing from memory without visual feedback (e.g. being blindfolded or using an inkless pen), can, in different patients, either decrease (Chokron, Colliot, \& Bartolomeo, 2004) or increase (Cristinzio et al., 2009) left omissions. These opposite influences may well result from a predominant influence of, respectively, MA or SWM deficits. Also, Pisella, Berberovic and Mattingley (2004) asked eight neglect patients to detect changes of spatial location, color or shape in one item in an array of four objects. All patients were impaired in detecting changes in left-sided items. However, four patients, all with parietal damage, had disproportionate impairment to detect changes in spatial location for both left-sided and right-sided items, suggesting a nonlateralized SWM deficit. However, in other studies the SWM deficit appeared to be restricted to, or increased for, left-sided items (D'Erme \& Bartolomeo, 1997; Denis, Beschin, Logie, \& Della Sala, 2002), perhaps reflecting an interaction with attentional deficits such as MA.

A limitation of our study is that our paradigm could not easily identify repeated touches on the same items. In principle, perseverative behavior could in part explain the 
frontal involvement that we found in the impaired SWM group. However, Parton et al. (2006) specifically explored revisiting behavior in 22 right-brain damaged patients, of whom 11 had signs of left neglect. Patients had to find targets among distractors. Similar to our paradigm, in different conditions the touched targets could remain unchanged, be tagged or disappear. In the no change condition, patients tended to retouch the unchanged targets; this phenomenon was especially evident for right-sided targets in neglect patients. However, most repeated touches were not immediate, but occurred after intervening touches on other targets. Thus, the authors concluded that this pattern of performance was not simply perseverative in nature, but resulted from a SWM deficit which interacted with neglect, consistent with the present results.

Wansard et al. (2014) evaluated SWM in 14 neglect patients by using a computerized version of the Corsi test (Corsi, 1972). Consistent with the present results, patients' performance showed signs of a (mainly lateralized) SWM impairment. This deficit did not depend on the hand motor response, because it was also present with verbal response, and was partially independent of perseverations of response. In a further study, Wansard et al. (2015) used similar, Corsi-style displays in two distinct conditions, with targets presented either in a simultaneous or in a sequential manner. Results showed again impaired performance in neglect patients, with instances of double dissociations of performance deficits, respectively involving found evidence for a double dissociation between distinct deficits of SWM, respectively involving processing of spatial configurations or serial order processing. The present procedure, which focused on simultaneously presented configurations of targets, did not allow us to discriminate between these putatively different deficits. 


\section{Clinical implications}

By using paper-and-pencil tests, Mark et al. (1988) emphasized that the effect of erasing progressively the right-sided stimuli was positive for neglect patients that could respond to more targets when the most rightward disappeared. Nonetheless, their patients had been studied in the acute post-stroke period and had presumably received no rehabilitation. In the present study, we could identify a predominant MA profile in two patients studied in the chronic stage, and having been rehabilitated by using classical paper-and-pencil procedures (P25) or prismatic adaptation (P6). Thus, MA may be observed even several years after the injury, and in spite of rehabilitation, although this is likely to be a rare occurrence. Of note, even after rehabilitation, patient $\mathrm{P} 25^{\prime}$ 's performance on paper and pencil tests with the presence of ipsilesional items was particularly impaired. This patient also showed perseverations on these tests, as well as a rightward starting point, which is one of the most sensitive markers of the presence (Azouvi et al., 2002) and persistence (Kettunen, Nurmi, Dastidar, \& Jehkonen, 2012) of left neglect.

However, except for these two patients with predominant MA, the present neglect patients performed better on the tag condition than on the no change condition, which suggests that in most patients tagged targets were unable to capture and maintain attention, or perhaps even helped in keeping track of the already detected targets (see (Cristinzio et al., 2009). The comparatively high frequency of SWM impairment observed in our sample may depend on the additional difficulty of remembering previously visited locations without external tags in the no change condition. In this sense, the no change condition might qualify as a dual task, because patients must update their visuospatial memory while searching for new targets. Dual task conditions are likely to uncover 
previously compensated forms of spatial bias in brain-damaged patients (Bartolomeo, 2000;

Bonato, Spironelli, Lisi, Priftis, \& Zorzi, 2015; van Kessel, Geurts, Brouwer, \& Fasotti, 2013;

van Kessel, van Nes, Geurts, Brouwer, \& Fasotti, 2013). On the other hand, an early rightward capture of attention may persist as a residual sign of spatial bias in patients who have learned to compensate for left neglect (Bartolomeo, 1997; Karnath, 1988). Thus, recovery of other component deficits of neglect, such as SWM impairment, may be important for clinical compensation of neglect. This recovery might also depend on the recruitment of left-hemisphere processes (Bartolomeo, 2015; Bartolomeo \& Thiebaut de Schotten, 2016), which would however require efficient inter-hemispheric interactions (Lunven et al., 2015).

\section{Anatomical considerations}

Although the anatomical study did not show clear-cut differences between MA and SWM deficits, patients with predominant MA presented lesions that concerned the inferior parietal lobule (P6) or less usual locations in neglect, such as the thalamus (P25). Damage in the lateral-dorsal portion of the thalamus, which connects the premotor cortex with the inferior parietal lobule, was described in a subset of neglect patients who did not display clear signs of fronto-parietal disconnection (Thiebaut de Schotten et al., 2014). The white matter dissection performed in P25 emphasized a disconnection at the level of both IFOF and ILF bundles. These lesional patterns are broadly consistent with those observed by Vossel and Fink (2016) in patients who could take advantage of a left-sided distractor to improve their response times to right-sided targets, perhaps because the left-sided distractor induced an unspecific saliency mechanism which can enhance MA from rightsided targets. Also the IFOF disconnection, already described in neglect patients (Toba, 
Migliaccio, et al., 2017; Urbanski et al., 2008) could contribute to MA by impairing the topdown modulation of right-sided visual areas from frontal cortex or the transmission of visual input to frontal areas important for general arousal (Doricchi et al., 2008). Among our patients with predominant SWM deficit, P13 and P20 had white matter disconnections of both the IFOF and the ILF. This anatomical pattern is similar to the one observed in P25 with predominant MA, who also had a strong asymmetry of FA values between the right and the left SLF. The role of lesions situated on the right SLF trajectory has already been emphasized in different studies (Bartolomeo, 2006a, 2007, 2014; Bartolomeo, Thiebaut de Schotten, \& Doricchi, 2007; Bartolomeo, Thiebaut de Schotten, \& Duffau, 2007; Corbetta \& Shulman, 2011; Doricchi et al., 2008; Doricchi \& Tomaiuolo, 2003; He et al., 2007; Shinoura et al., 2009; Thiebaut de Schotten et al., 2005; Toba, Migliaccio, et al., 2017; Toba, Zavaglia, et al., 2017; Vaessen, Saj, Lovblad, Gschwind, \& Vuilleumier, 2016). Although more anatomical evidence is clearly needed to draw general conclusions (Bartolomeo, Seidel Malkinson, \& de Vito, 2016), it remains possible that both behavioral deficits depend on damage on partially overlapping brain networks. In the present study, we did not find a clear anatomical dissociation between MA and SWM deficit. Previous studies suggested the possibility of partial dissociations. Evidence from a recent study (Pisella, Biotti, \& Vighetto, 2015) suggested a simple dissociation between the attentional component and visual remapping/SWM deficit in neurodegenerative patients with posterior cortical atrophy (PCA). While attentional deficits were emphasized in patients with mild symptoms presenting atrophy mainly in the superior parietal lobule (SPL), both attentional and SWM impairment were observed in more severely impaired patients presenting atrophy in both inferior and superior parietal lobules. This simple dissociation may be due to the fact that anatomical degeneration in PCA slowly extends from the SPL to more ventral regions (Kas et al., 2011). 
Simple dissociations have also been observed in stroke patients. Damage to IPL can lead to functional hypoactivation of the ipsilateral SPL and signs of left neglect (Corbetta, Kincade, Lewis, Snyder, \& Sapir, 2005). Pure SPL damage can instead provoke attentional deficits with sub-clinical neglect (Gillebert et al., 2011). A reverse dissociation could be inferred from the study of Russell et al. (2010). These authors described an isolated SWM/visual remapping deficit in patients exhibiting constructional apraxia after recovery from neglect. In this case the lesions were limited to the right IPL. Furthermore, functional magnetic resonance imaging and transcranial magnetic stimulation studies consistently showed that SWM (including visual remapping) seems to rely more on specialized networks of the right hemisphere (Malhotra, Coulthard, \& Husain, 2009; Pisella et al., 2011; Prime, Vesia, \& Crawford, 2008; van Koningsbruggen, Gabay, Sapir, Henik, \& Rafal, 2010), while attention relies on a symmetrical bilateral dorsal attentional network (Corbetta \& Shulman, 2011, but see Bourgeois, Chica, Valero-Cabre, \& Bartolomeo, 2013a, 2013b; Nobre, 2001 for possible asymmetries of the dorsal attentional network and Chica, Bourgeois, \& Bartolomeo, 2014 for the possible implication of the right ventral attention network in attentional orienting).

\section{Conclusions and perspectives}

Thanks to advanced behavioral testing techniques and analysis algorithms, we have demonstrated that the some of the neglect patients in our unselected, prospectively recruited group presented signs of MA or SWM deficit. These findings support and specify multi-component models of neglect, which postulate that neglect behavior results from variable combinations of component deficits in different patients (Barbieri \& De Renzi, 1989; Bartolomeo, 2007, 2014; Binder et al., 1992; Heilman et al., 2002; M. M. Mesulam, 2002; Nachev \& Husain, 2006; Vallar, 1998). Specifically, our multiple single-case approach was 
able to identify patients with variable severity of combined MA and SWM deficits. To overcome the inherent limitations of anatomo-clinical correlations based on vascular lesions (Bartolomeo, 2011; Godefroy et al., 1998; Mah, Husain, Rees, \& Nachev, 2014), future studies should study with similar techniques patients with different etiologies, such as neurodegenerative conditions (see Bartolomeo \& Migliaccio, 2016, for review). 
Acknowledgements

We thank the patients for their patience and cooperation, Dr. Francesca Ciaraffa for help in acquiring patients' data, and Bastien Oliviero for help in setting the experimental procedures. We also thank Mario Bonato and two anonymous reviewers for helpful comments on a previous version of the manuscript. This work has received support from the program "Investissements d'Avenir" ANR-10-IAIHU-06. MNT was supported by a doctoral grant from the French Ministry of Research. MR was supported by funds from the Italian Ministry of Health (Ricerca Corrente). 


\section{References}

Albert, M. L. (1973). A simple test of visual neglect. Neurology, 23, 658-664.

Awh, E., \& Jonides, J. (2001). Overlapping mechanisms of attention and spatial working memory. Trends Cogn Sci, 5(3), 119-126.

Azouvi, P., Samuel, C., Louis-Dreyfus, A., Bernati, T., Bartolomeo, P., Beis, J.-M., . . Rousseaux, M. (2002). Sensitivity of clinical and behavioural tests of spatial neglect after right hemisphere stroke. Journal of Neurology, Neurosurgery and Psychiatry, 73(2), 160-166.

Barbieri, C., \& De Renzi, E. (1989). Patterns of neglect dissociation. Behavioural Neurology, 2, 13-14.

Bartolomeo, P. (1997). The novelty effect in recovered hemineglect. Cortex, 33(2), 323-332.

Bartolomeo, P. (2000). Inhibitory processes and compensation for spatial bias after right hemisphere damage. Neuropsychological Rehabilitation, 10(5), 511-526.

Bartolomeo, P. (2006a). A parieto-frontal network for spatial awareness in the right hemisphere of the human brain. Archives of Neurology, 63, 1238-1241.

Bartolomeo, P. (2006b). A parietofrontal network for spatial awareness in the right hemisphere of the human brain. Arch Neurol, 63(9), 1238-1241.

Bartolomeo, P. (2007). Visual neglect. [Review]. Current Opinion in Neurology, 20(4), 381-386.

Bartolomeo, P. (2011). The quest for the 'critical lesion site' in cognitive deficits: problems and perspectives. [Comment]. Cortex, 47(8), 1010-1012.

Bartolomeo, P. (2014). Attention disorders after right brain damage: Living in halved worlds. London.

Bartolomeo, P. (2015). Spatially biased decisions: Toward a dynamic interactive model of visual neglect. In J. Y. Tracy, B. Hampstead \& K. Sathian (Eds.), Plasticity of Cognition in Neurologic Disorders (pp. 299-322). Oxford: Oxford University Press.

Bartolomeo, P., D'Erme, P., \& Gainotti, G. (1994). The relationship between visuospatial and representational neglect. Neurology, 44(9), 1710-1714.

Bartolomeo, P., \& Migliaccio, R. (2016). Disorders of attentional processes. In M. Husain \& J. Schott (Eds.), Oxford textbook of Cognitive Neurology and Dementia (pp. 161-171). Oxford: Oxford University Press.

Bartolomeo, P., Seidel Malkinson, T., \& de Vito, S. (2016). Botallo's error, or the quandaries of the universality assumption. [Review]. Cortex.

Bartolomeo, P., \& Thiebaut de Schotten, M. (2016). Let thy left brain know what thy right brain doeth: Inter-hemispheric compensation of functional deficits after brain damage. Neuropsychologia.

Bartolomeo, P., Thiebaut de Schotten, M., \& Doricchi, F. (2007). Left unilateral neglect as a disconnection syndrome. Cereb Cortex, 17(11), 2479-2490.

Bartolomeo, P., Thiebaut de Schotten, M., \& Duffau, H. (2007). Mapping of visuo-spatial functions during brain surgery: a new tool to prevent unilateral spatial neglect. Neurosurgery, 61(6), E1340.

Bartolomeo, P., Urbanski, M., Chokron, S., Chainay, H., Moroni, C., Sieroff, E., . . Halligan, P. (2004). Neglected attention in apparent spatial compression. Neuropsychologia, 42(1), 49-61.

Basser, P. J., Mattiello, J., \& LeBihan, D. (1994). Estimation of the effective self-diffusion tensor from the NMR spin echo. Journal of Magnetic Resonance, Series B, 103(3), 247-254.

Basser, P. J., \& Pierpaoli, C. (1996). Microstructural and physiological features of tissues elucidated by quantitative-diffusion-tensor MRI. J Magn Reson B, 111(3), 209-219.

Binder, J., Marshall, R., Lazar, R., Benjamin, J., \& Mohr, J. P. (1992). Distinct syndromes of hemineglect. Archives of Neurology, 49(11), 1187-1194.

Bonato, M. (2012). Neglect and extinction depend greatly on task demands: a review. Front Hum Neurosci, 6, 195. doi: 10.3389/fnhum.2012.00195

Bonato, M., Spironelli, C., Lisi, M., Priftis, K., \& Zorzi, M. (2015). Effects of Multimodal Load on Spatial Monitoring as Revealed by ERPs. [Research Support, Non-U.S. Gov't]. PLoS One, 10(9), e0136719. doi: 10.1371/journal.pone.0136719 
Bourgeois, A., Chica, A. B., Migliaccio, R., Bayle, D. J., Duret, C., Pradat-Diehl, P., . . Bartolomeo, P. (2015). Inappropriate rightward saccades after right hemisphere damage: Oculomotor analysis and anatomical correlates. Neuropsychologia, 73, 1-11.

Bourgeois, A., Chica, A. B., Valero-Cabre, A., \& Bartolomeo, P. (2013a). Cortical control of inhibition of return: causal evidence for task-dependent modulations by dorsal and ventral parietal regions. [Clinical Trial

Research Support, Non-U.S. Gov't]. Cortex, 49(8), 2229-2238. doi: 10.1016/j.cortex.2012.10.017

Bourgeois, A., Chica, A. B., Valero-Cabre, A., \& Bartolomeo, P. (2013b). Cortical control of Inhibition of Return: exploring the causal contributions of the left parietal cortex. [Research Support, Non-U.S. Gov't]. Cortex, 49(10), 2927-2934. doi: 10.1016/j.cortex.2013.08.004

Brett, M., Leff, A. P., Rorden, C., \& Ashburner, J. (2001). Spatial normalization of brain images with focal lesions using cost function masking. Neuroimage, 14(2), 486-500.

Catani, M., Howard, R. J., Pajevic, S., \& Jones, D. K. (2002). Virtual in vivo interactive dissection of white matter fasciculi in the human brain. Neuroimage, 17(1), 77-94.

Catani, M., Jones, D. K., \& ffytche, D. H. (2005). Perisylvian language networks of the human brain. Annals of Neurology, 57(1), 8-16.

Catani, M., \& Thiebaut de Schotten, M. (2008). A diffusion tensor imaging tractography atlas for virtual in vivo dissections. Cortex, 44(8), 1105-1132.

Charras, P., Lupianez, J., Migliaccio, R., Toba, M., Pradat-Diehl, P., Duret, C., \& Bartolomeo, P. (2012). Dissecting the component deficits of perceptual imbalance in visual neglect: evidence from horizontal-vertical length comparisons. [Research Support, Non-U.S. Gov't]. Cortex, 48(5), 540-552. doi: 10.1016/j.cortex.2011.01.008

Chica, A. B., Bourgeois, A., \& Bartolomeo, P. (2014). On the role of the ventral attention system in spatial orienting. Front Hum Neurosci, 8, 235. doi: 10.3389/fnhum.2014.00235

Chica, A. B., Thiebaut de Schotten, M., Toba, M., Malhotra, P., Lupianez, J., \& Bartolomeo, P. (2012). Attention networks and their interactions after right-hemisphere damage. Cortex, 48(6), 654663.

Chokron, S., Colliot, P., \& Bartolomeo, P. (2004). The role of vision in spatial representation. Cortex, 40(2), 281-290.

Corbetta, M., Kincade, M. J., Lewis, C., Snyder, A. Z., \& Sapir, A. (2005). Neural basis and recovery of spatial attention deficits in spatial neglect. Nature Neuroscience, 8(11), 1603-1610.

Corbetta, M., \& Shulman, G. L. (2011). Spatial neglect and attention networks. [Research Support, N.I.H., Extramural

Review]. Annu Rev Neurosci, 34, 569-599. doi: 10.1146/annurev-neuro-061010-113731

Corsi, P. (1972). Human memory and the medial temporal region of the brain. Dissertation Abstracts International, 34(2).

Coulthard, E., Parton, A., \& Husain, M. (2007). The modular architecture of the neglect syndrome: Implications for action control in visual neglect. Neuropsychologia, doi:10.1016/j.neuropsychologia.2007.1001.1020.

Crawford, J. R., Garthwaite, P. H., \& Porter, S. (2010). Point and interval estimates of effect sizes for the case-controls design in neuropsychology: rationale, methods, implementations, and proposed reporting standards. Cogn Neuropsychol, 27(3), 245-260.

Cristinzio, C., Bourlon, C., Pradat-Diehl, P., Trojano, L., Grossi, D., Chokron, S., \& Bartolomeo, P. (2009). Representational neglect in "invisible" drawing from memory. Cortex, 45(3), 313-317.

D'Erme, P., \& Bartolomeo, P. (1997). A unilateral defect of short-term visual memory in left hemineglect. European Journal of Neurology, 4, 382-386.

De Renzi, E., Gentilini, M., Faglioni, P., \& Barbieri, C. (1989). Attentional shifts toward the rightmost stimuli in patients with left visual neglect. Cortex, 25, 231-237. 
Denis, M., Beschin, N., Logie, R. H., \& Della Sala, S. (2002). Visual perception and verbal descriptions as sources for generating mental representations: Evidence from representational neglect. Cognitive Neuropsychology, 19(2), 97-112.

Doricchi, F., Thiebaut de Schotten, M., Tomaiuolo, F., \& Bartolomeo, P. (2008). White matter (dis)connections and gray matter (dys)functions in visual neglect: gaining insights into the brain networks of spatial awareness. Cortex, 44(8), 983-995.

Doricchi, F., \& Tomaiuolo, F. (2003). The anatomy of neglect without hemianopia: a key role for parietal-frontal disconnection? NeuroReport, 14(17), 2239-2243.

Gainotti, G., D'Erme, P., \& Bartolomeo, P. (1991). Early orientation of attention toward the half space ipsilateral to the lesion in patients with unilateral brain damage. Journal of Neurology, Neurosurgery and Psychiatry, 54, 1082-1089.

Gainotti, G., Perri, R., \& Cappa, A. (2002). Left hand movements and right hemisphere activation in unilateral spatial neglect: a test of the interhemispheric imbalance hypothesis. Neuropsychologia, 40(8), 1350-1355.

Gillebert, C. R., Mantini, D., Thijs, V., Sunaert, S., Dupont, P., \& Vandenberghe, R. (2011). Lesion evidence for the critical role of the intraparietal sulcus in spatial attention. [Randomized Controlled Trial

Research Support, Non-U.S. Gov't]. Brain, 134(Pt 6), 1694-1709. doi: 10.1093/brain/awr085

Godefroy, O., Duhamel, A., Leclerc, X., Saint Michel, T., Henon, H., \& Leys, D. (1998). Brain-behaviour relationships. Some models and related statistical procedures for the study of brain-damaged patients. Brain, 121 ( Pt 8), 1545-1556.

Gorgoraptis, N., Mah, Y. H., Machner, B., Singh-Curry, V., Malhotra, P., Hadji-Michael, M., ... Husain, M. (2012). The effects of the dopamine agonist rotigotine on hemispatial neglect following stroke. Brain, 135(Pt 8), 2478-2491.

Halligan, P. W., \& Bartolomeo, P. (2012). Visual Neglect. In V. S. Ramachandran (Ed.), Encyclopedia of Human Behavior (2nd ed., Vol. 3, pp. 652-664): Academic Press.

He, B. J., Snyder, A. Z., Vincent, J. L., Epstein, A., Shulman, G. L., \& Corbetta, M. (2007). Breakdown of functional connectivity in frontoparietal networks underlies behavioral deficits in spatial neglect. Neuron, 53(6), 905-918.

Heilman, K. M., Watson, R. T., \& Valenstein, E. (1993). Neglect and related disorders. In K. M. Heilman \& E. Valenstein (Eds.), Clinical Neuropsychology (3rd ed., pp. 279-336). New York: Oxford University Press.

Heilman, K. M., Watson, R. T., \& Valenstein, E. (2002). Spatial neglect. In H. O. Karnath, D. Milner \& G. Vallar (Eds.), The Cognitive and Neural Bases of Spatial Neglect (pp. 3-30). Oxford: Oxford University Press.

Husain, M., Mannan, S., Hodgson, T., Wojciulik, E., Driver, J., \& Kennard, C. (2001). Impaired spatial working memory across saccades contributes to abnormal search in parietal neglect. Brain, 124(Pt 5), 941-952.

Karnath, H.-O. (1988). Deficits of attention in acute and recovered hemi-neglect. Neuropsychologia, 20, 27-45.

Kas, A., de Souza, L. C., Samri, D., Bartolomeo, P., Lacomblez, L., Kalafat, M., . . Sarazin, M. (2011). Neural correlates of cognitive impairment in posterior cortical atrophy. [Research Support, Non-U.S. Gov't]. Brain, 134(Pt 5), 1464-1478. doi: 10.1093/brain/awr055

Keller, I., Volkening, K., \& Garbacenkaite, R. (2015). Stimulus-dependent modulation of visual neglect in a touch-screen cancellation task. Neuropsychology, 29(3), 417-420.

Kettunen, J. E., Nurmi, M., Dastidar, P., \& Jehkonen, M. (2012). Recovery from visual neglect after right hemisphere stroke: does starting point in cancellation tasks change after 6 months? Clin Neuropsychol, 26(2), 305-320.

Kristjansson, A., \& Vuilleumier, P. (2010). Disruption of spatial memory in visual search in the left visual field in patients with hemispatial neglect. Vision Res, 50(14), 1426-1435. 
Le Bihan, D., Mangin, J., Poupon, C., Clark, C., Pappata, S., Molko, N., \& Chabriat, H. (2001). Diffusion tensor imaging: concepts and applications. Journal of Magnetic Resonance Imaging, 13, 534546.

Lunven, M., Thiebaut De Schotten, M., Bourlon, C., Duret, C., Migliaccio, R., Rode, G., \& Bartolomeo, P. (2015). White matter lesional predictors of chronic visual neglect: a longitudinal study. Brain, 138(Pt 3), 746-760.

Mah, Y. H., Husain, M., Rees, G., \& Nachev, P. (2014). Human brain lesion-deficit inference remapped. Brain, 137(Pt 9), 2522-2531.

Malhotra, P., Coulthard, E. J., \& Husain, M. (2009). Role of right posterior parietal cortex in maintaining attention to spatial locations over time. [Research Support, Non-U.S. Gov't]. Brain, 132(Pt 3), 645-660. doi: 10.1093/brain/awn350

Malhotra, P., Jager, H. R., Parton, A., Greenwood, R., Playford, E. D., Brown, M. M., . . Husain, M. (2005). Spatial working memory capacity in unilateral neglect. Brain, 128(Pt 2), 424-435.

Mark, V. W., Kooistra, C. A., \& Heilman, K. M. (1988). Hemispatial neglect affected by non-neglected stimuli. Neurology, 38(8), 640-643.

Mesulam, M. M. (1981). A cortical network for directed attention and unilateral neglect. Annals of Neurology, 10, 309-325.

Mesulam, M. M. (1985). Principles of Behavioral Neurology. Philadelphia (PA): F.A. Davis.

Mesulam, M. M. (2000). Principles of behavioral and cognitive neurology. Oxford: Oxford University Press.

Mesulam, M. M. (2002). Functional anatomy of attention and neglect: from neurons to networks. In H. O. Karnath, D. Milner \& G. Vallar (Eds.), The Cognitive and Neural Bases of Spatial Neglect (pp. 33-45). Oxford: Oxford University Press.

Nachev, P., \& Husain, M. (2006). Disorders of visual attention and the posterior parietal cortex. Cortex, 42(5), 766-773.

Nobre, A. C. (2001). The attentive homunculus: now you see it, now you don't. Neuroscience and Biobehavioral Reviews, 25(6), 477-496.

Parton, A., Malhotra, P., \& Husain, M. (2004). Hemispatial neglect. Journal of Neurology, Neurosurgery and Psychiatry, 75(1), 13-21.

Parton, A., Malhotra, P., Nachev, P., Ames, D., Ball, J., Chataway, J., \& Husain, M. (2006). Space reexploration in hemispatial neglect. [Research Support, Non-U.S. Gov't]. Neuroreport, 17(8), 833-836. doi: 10.1097/01.wnr.0000220130.86349.a7

Pisella, L., Alahyane, N., Blangero, A., Thery, F., Blanc, S., \& Pelisson, D. (2011). Right-hemispheric dominance for visual remapping in humans. [Review]. Philos Trans $R$ Soc Lond B Biol Sci, 366(1564), 572-585. doi: 10.1098/rstb.2010.0258

Pisella, L., Berberovic, N., \& Mattingley, J. B. (2004). Impaired working memory for location but not for colour or shape in visual neglect: a comparison of parietal and non-parietal lesions. Cortex, 40(2), 379-390.

Pisella, L., Biotti, D., \& Vighetto, A. (2015). Combination of attentional and spatial working memory deficits in Balint-Holmes syndrome. [Randomized Controlled Trial

Research Support, Non-U.S. Gov't]. Ann N Y Acad Sci, 1339, 165-175. doi: 10.1111/nyas.12731

Pisella, L., \& Mattingley, J. B. (2004). The contribution of spatial remapping impairments to unilateral visual neglect. [Review]. Neurosci Biobehav Rev, 28(2), 181-200. doi: 10.1016/j.neubiorev.2004.03.003

Posner, M. I., Walker, J. A., Friedrich, F. J., \& Rafal, R. D. (1984). Effects of parietal injury on covert orienting of attention. Journal of Neuroscience, 4, 1863-1874.

Prime, S. L., Vesia, M., \& Crawford, J. D. (2008). Transcranial magnetic stimulation over posterior parietal cortex disrupts transsaccadic memory of multiple objects. [Research Support, NonU.S. Gov't]. J Neurosci, 28(27), 6938-6949. doi: 10.1523/JNEUROSCI.0542-08.2008 
Rabuffetti, M., Farina, E., Alberoni, M., Pellegatta, D., Appollonio, I., Affanni, P., . . Ferrarin, M. (2012). Spatio-temporal features of visual exploration in unilaterally brain-damaged subjects with or without neglect: results from a touchscreen test. PLoS One, 7(2), e31511.

Rastelli, F., Funes, M. J., Lupiáñez, J., Duret, C., \& Bartolomeo, P. (2008). Left neglect: Is the disengage deficit space- or object-based? Experimental Brain Research, 187(3), 439-446.

Robertson, I. H., Mattingley, J. B., Rorden, C., \& Driver, J. (1998). Phasic alerting of neglect patients overcomes their spatial deficit in visual awareness. Nature, 395(6698), 169-172.

Rorden, C., \& Karnath, H. O. (2010). A simple measure of neglect severity. Neuropsychologia, 48(9), 2758-2763.

Russell, C., Deidda, C., Malhotra, P., Crinion, J. T., Merola, S., \& Husain, M. (2010). A deficit of spatial remapping in constructional apraxia after right-hemisphere stroke. [Comparative Study

Multicenter Study

Research Support, Non-U.S. Gov't]. Brain, 133(Pt 4), 1239-1251. doi: 10.1093/brain/awq052

Shinoura, N., Suzuki, Y., Yamada, R., Tabei, Y., Saito, K., \& Yagi, K. (2009). Damage to the right superior longitudinal fasciculus in the inferior parietal lobe plays a role in spatial neglect. Neuropsychologia, 47(12), 2600-2603. doi: S0028-3932(09)00220-6 [pii]

10.1016/j.neuropsychologia.2009.05.010

Thiebaut de Schotten, M., Dell'Acqua, F., Forkel, S. J., Simmons, A., Vergani, F., Murphy, D. G., \& Catani, M. (2011). A lateralized brain network for visuospatial attention. Nat Neurosci, 14(10), 1245-1246.

Thiebaut de Schotten, M., Kinkingnehun, S., Delmaire, C., Lehericy, S., Duffau, H., Thivard, L., . . . Bartolomeo, P. (2008). Visualization of disconnection syndromes in humans. Cortex, 44(8), 1097-1103.

Thiebaut de Schotten, M., Tomaiuolo, F., Aiello, M., Merola, S., Silvetti, M., Lecce, F., ... Doricchi, F. (2014). Damage to white matter pathways in subacute and chronic spatial neglect: a group study and 2 single-case studies with complete virtual "in vivo" tractography dissection. Cereb Cortex, 24(3), 691-706.

Thiebaut de Schotten, M., Urbanski, M., Duffau, H., Volle, E., Levy, R., Dubois, B., \& Bartolomeo, P. (2005). Direct evidence for a parietal-frontal pathway subserving spatial awareness in humans. Science, 309(5744), 2226-2228. doi: 309/5744/2226 [pii]

10.1126/science.1116251

Toba, M. N., Migliaccio, R., Batrancourt, B., Bourlon, C., Duret, C., Pradat-Diehl, P., . . Bartolomeo, P. (2017). Common brain networks for distinct deficits in visual neglect. A combined structural and tractography MRI approach. Neuropsychologia. doi: 10.1016/j.neuropsychologia.2017.10.018

Toba, M. N., Zavaglia, M., Rastelli, F., Valabregue, R., Pradat-Diehl, P., Valero-Cabre, A., \& Hilgetag, C. C. (2017). Game theoretical mapping of causal interactions underlying visuo-spatial attention in the human brain based on stroke lesions. Hum Brain Mapp. doi: 10.1002/hbm.23601

Urbanski, M., Thiebaut de Schotten, M., Rodrigo, S., Catani, M., Oppenheim, C., Touze, E., ... Bartolomeo, P. (2008). Brain networks of spatial awareness: evidence from diffusion tensor imaging tractography. J Neurol Neurosurg Psychiatry, 79(5), 598-601.

Vaessen, M. J., Saj, A., Lovblad, K. O., Gschwind, M., \& Vuilleumier, P. (2016). Structural white-matter connections mediating distinct behavioral components of spatial neglect in right braindamaged patients. [Research Support, Non-U.S. Gov't]. Cortex, 77, 54-68. doi: 10.1016/j.cortex.2015.12.008

Vallar, G. (1998). Spatial hemineglect in humans. Trends in Cognitive Sciences, 2, 87-97.

van Kessel, M. E., Geurts, A. C., Brouwer, W. H., \& Fasotti, L. (2013). Visual Scanning Training for Neglect after Stroke with and without a Computerized Lane Tracking Dual Task. Front Hum Neurosci, 7, 358. doi: 10.3389/fnhum.2013.00358 
van Kessel, M. E., van Nes, I. J., Geurts, A. C., Brouwer, W. H., \& Fasotti, L. (2013). Visuospatial asymmetry in dual-task performance after subacute stroke. [Research Support, Non-U.S. Gov't]. J Neuropsychol, 7(1), 72-90. doi: 10.1111/j.1748-6653.2012.02036.x

van Koningsbruggen, M. G., Gabay, S., Sapir, A., Henik, A., \& Rafal, R. D. (2010). Hemispheric asymmetry in the remapping and maintenance of visual saliency maps: a TMS study. [Research Support, Non-U.S. Gov't]. J Cogn Neurosci, 22(8), 1730-1738. doi: 10.1162/jocn.2009.21356

Verdon, V., Schwartz, S., Lovblad, K. O., Hauert, C. A., \& Vuilleumier, P. (2010). Neuroanatomy of hemispatial neglect and its functional components: a study using voxel-based lesionsymptom mapping. Brain, 133(Pt 3), 880-894.

Vossel, S., \& Fink, G. R. (2016). Contralesional distractors enhance ipsilesional target processing after right-hemispheric stroke. Cortex, 78, 115-124.

Wansard, M., Bartolomeo, P., Bastin, C., Segovia, F., Gillet, S., Duret, C., \& Meulemans, T. (2015). Support for distinct subcomponents of spatial working memory: a double dissociation between spatial-simultaneous and spatial-sequential performance in unilateral neglect. Cogn Neuropsychol, 32(1), 14-28.

Wansard, M., Meulemans, T., Gillet, S., Segovia, F., Bastin, C., Toba, M. N., \& Bartolomeo, P. (2014). Visual neglect: is there a relationship between impaired spatial working memory and recancellation? Exp Brain Res, 232(10), 3333-3343.

Wojciulik, E., Husain, M., Clarke, K., \& Driver, J. (2001). Spatial working memory deficit in unilateral neglect. Neuropsychologia, 39(4), 390-396.

Wojciulik, E., Rorden, C., Clarke, K., Husain, M., \& Driver, J. (2004). Group study of an "undercover" test for visuospatial neglect: invisible cancellation can reveal more neglect than standard cancellation. Journal of Neurology, Neurosurgery and Psychiatry, 75(9), 1356-1358. 


\section{Figure legends}

Figure 1

Example of the computerized task with the three different conditions used in the study: $(A)$ no change (targets touched by patients remained unchanged); (B) tag (targets become more perceptually salient upon being touched); (C) disappear (targets vanish with the touch). Figure 2

Graphical plot of the search performances of a patient without neglect on the three test conditions: no change, tag, disappear. The green $X$ denotes the first touched target, the thin dotted lines mark the search path. The vertical thick dotted line marks the latency-weighted average position of all the detected targets.

Figure 3

Latency-weighted average score obtained by non-neglect patients and by neglect patients under the three task conditions. The higher the scores, the larger the patients' rightward bias (left neglect). Error bars represent 95\% confidence intervals.

Figure 4

Scatterplot of the differential indexes obtained by neglect patients (circles) and by nonneglect patients (triangles). Dotted lines indicate cutoff scores based on the performance of non-neglect patients. Neglect patients' patterns of performance falling outside the cutoff scores are marked by the patients' numeric codes. The areas identifying predominant MA and SWM deficits are labeled as such.

Figure 5 
Overlap of the brain lesions for all the 27 unilateral neglect patients (z-coordinates from - 30 to 35 in MNI space). The color range indicates the proportion of overlap between patients (red, $100 \%$ overlap).

Figure 6

Lesions of patients with predominant MA (P25), predominant SWM deficit (P13, P20, P23, P28 and P31) and patients with impaired SWM and right-sided starting point in exploration (P4 and P8) (z-coordinates from -14 to 39 in MNI space).

Supplementary figures

Figure S1

Individual patterns of performance of patients in the MA group: (A) consistent pattern of performance; (B) (occasional) paradoxical patterns performance.

Figure S2

Individual patterns of performance of patients in the SWM deficit group: (A) consistent pattern of performance; (B) patients with impaired SWM patterns of performance and rightsided starting point in exploration and; (C) paradoxical patterns of performance.

Figure S3

Reconstruction of the main white matter bundles (from top to bottom: SLF, IFOF, ILF) in the right and in the left hemisphere of (A) a patient with predominant MA deficit (P25); and (B) a patient with predominant SWM deficit (P13). White matter tracts are rendered as FA maps 
for each hemisphere on the coregistered T1-weighted images. FA values are color-coded from yellow (lower values) to dark red (higher values).

Figure S4

FA extracted values in a patient presenting a predominant MA behavioral pattern (P25) and patients presenting predominant SWM impairment behavioral pattern (P13, P20, P28, P31). Note that in several patients the right IFOF and the right ILF are missing (see Figure 6 for lesion plots in these patients). Error bars represent SD. SLF, superior longitudinal fasciculus; IFOF, inferior fronto-occipital fasciculus; ILF, inferior longitudinal fasciculus; FA, fractional anisotropy. 
Table 1

Demographical and clinical characteristics of neglect patients included in the study

\begin{tabular}{lc} 
& Group Neglect + \\
\hline $\mathrm{n}$ & 33 \\
Sex: M/F & $21 / 12$ \\
Age (years) & $64.03 \pm 13.85$ \\
Education (years) & $8.81 \pm 5.38$ \\
Aetiology: infarct/haemorrhage & $23 / 10$ \\
Onset of illness (days) & 146.24 \\
Line cancellation (left/right hits, max=30/30) & $20.69 \pm 11.93 / 26.69 \pm 6.77$ \\
Letter cancellation (left/right hits, max=30/30) & $14 \pm 12.48 / 21.93 \pm 9.34$ \\
Bells cancellation (left/right hits, max=15/15) & $6.97 \pm 7.56 / 11.90 \pm 5.91$ \\
Line bisection (mm of rightward deviation for $200 \mathrm{~mm}$ lines) & $10.07 \pm 17.02$ \\
Line bisection (\% of deviation) & $23.82 \pm 27.52$ \\
Landscape drawing score (max=4) & $1.82 \pm 1.74$ \\
Overlapping figures (left/right hits, max=8/8) & $6.93 \pm 1.93 / 6.63 \pm 2.39$
\end{tabular}

Text reading (left/right hits, $\max =61 / 55$ )

$46.73 \pm 20.58 / 46.08 \pm 18.48$ 
Table 2

\section{Anatomical data of neglect patients}

\begin{tabular}{|c|c|}
\hline Patient & Grey matter lesion site \\
\hline P4 & $\begin{array}{l}\text { Inferior, middle and superior frontal gyri, anterior and middle cingulate, } \\
\text { precentral/postcentral cortex, supplementary motor area, superior temporal gyrus, } \\
\text { insula, rolandic operculum, supramarginal gyrus }\end{array}$ \\
\hline P8 & $\begin{array}{l}\text { Inferior frontal, postcentral cortex, superior, middle and inferior temporal gyri, } \\
\text { temporal pole, hippocampus and parahippocampal area, insula, rolandic operculum, } \\
\text { Heschl gyrus, amygdala, putamen, caudate nucleus, angular and supramarginal gyri, } \\
\text { inferior and middle occipital gyri, fusiform and lingual gyri, calcarine cortex, vermis, } \\
\text { cerebellum }\end{array}$ \\
\hline P13 & $\begin{array}{l}\text { Postcentral cortex, superior, middle and inferior temporal gyri, temporal pole, } \\
\text { hippocampus and parahippocampal area, insula, rolandic operculum, amygdala, } \\
\text { putamen, caudate nucleus, thalamus, angular and supramarginal gyri, superior and } \\
\text { middle occipital gyri, fusiform gyrus, calcarine cortex }\end{array}$ \\
\hline P20 & $\begin{array}{c}\text { Precentral/ postcentral cortex, superior, middle and inferior temporal gyri, temporal } \\
\text { pole, hippocampus and parahippocampal area, insula, rolandic operculum, caudate } \\
\text { nucleus, thalamus, precuneus, fusiform gyrus, calcarine cortex }\end{array}$ \\
\hline P23 & $\begin{array}{c}\text { Inferior frontal gyrus, hippocampus, insula, rolandic operculum, amygdala, putamen, } \\
\text { caudate nucleus, thalamus }\end{array}$ \\
\hline P25 & Thalamus, temporal superior, middle and inferior \\
\hline P28 & $\begin{array}{l}\text { Inferior frontal gyrus, superior temporal gyrus, temporal pole, insula, rolandic } \\
\text { operculum, amygdala, putamen, caudate nucleus, thalamus }\end{array}$ \\
\hline P31 & $\begin{array}{l}\text { Inferior, middle and superior frontal gyri, precentral/ postcentral cortex, paracentral } \\
\text { lobule, superior and middle temporal gyri, temporal pole, insula, rolandic operculum, } \\
\text { Heschl gyrus, putamen, cuneus, superior and inferior parietal cortex, angular and } \\
\text { supramarginal gyri, superior and middle occipital gyri, calcarine cortex }\end{array}$ \\
\hline
\end{tabular}


Figure 1

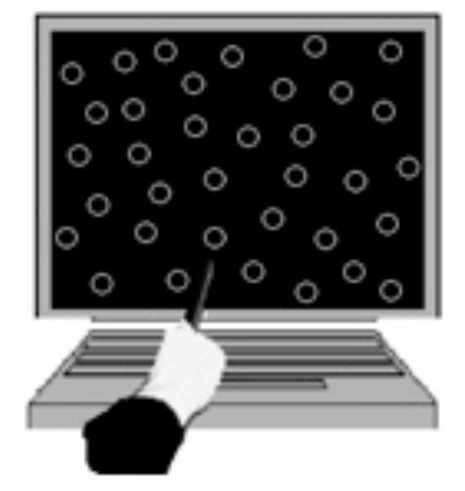

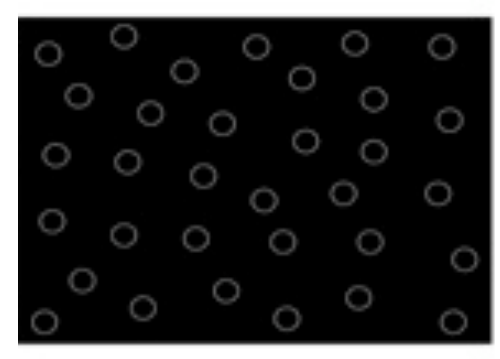

A

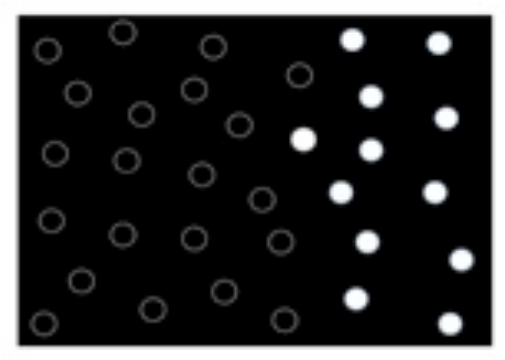

B

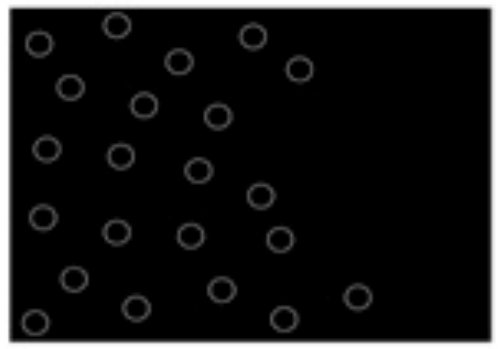

C

Figure 2
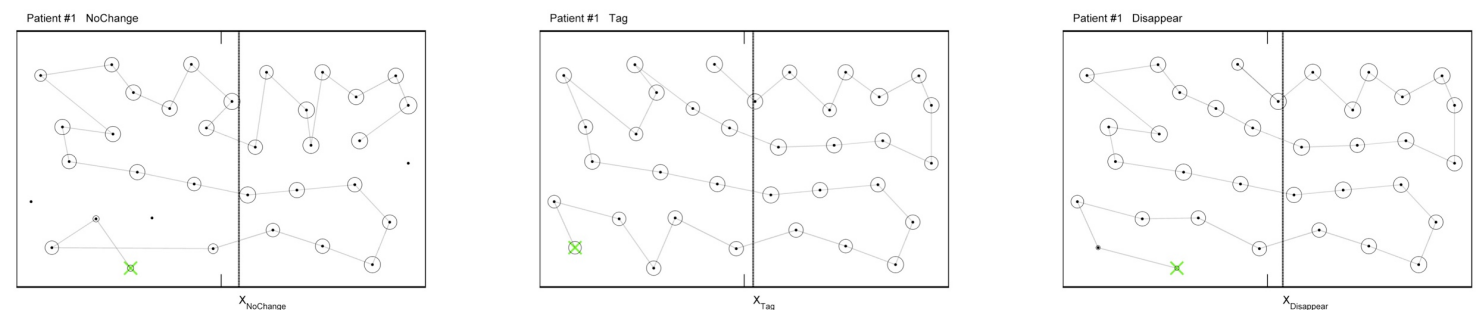
Figure 3

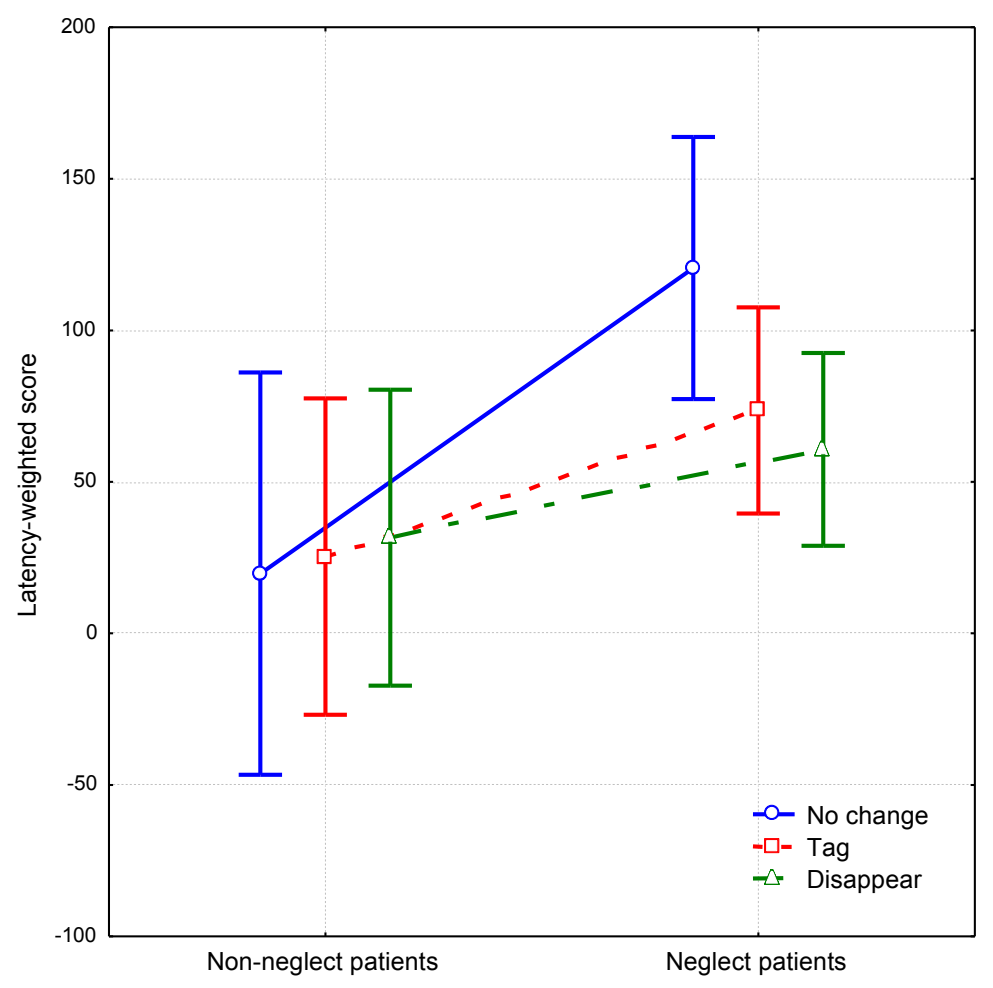


Figure 4

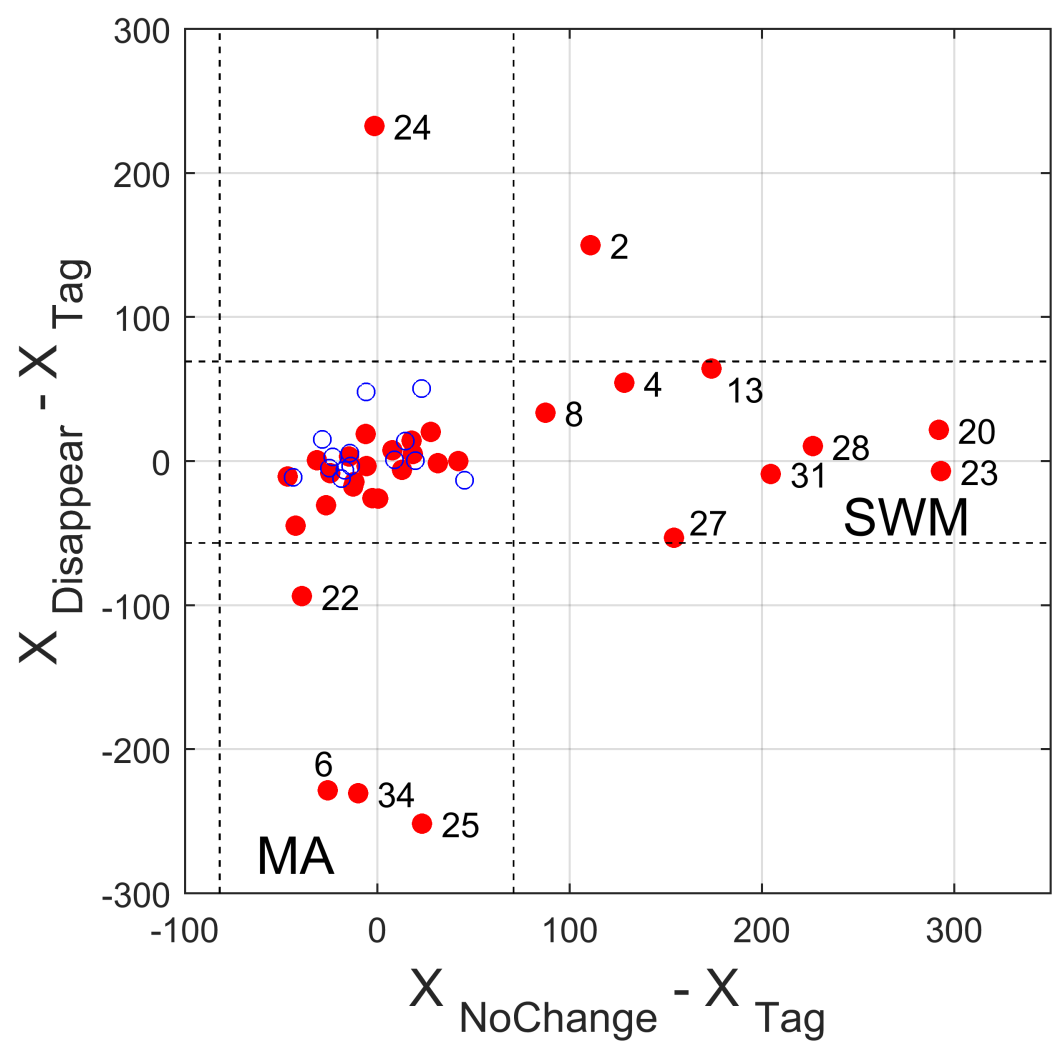

Figure 5

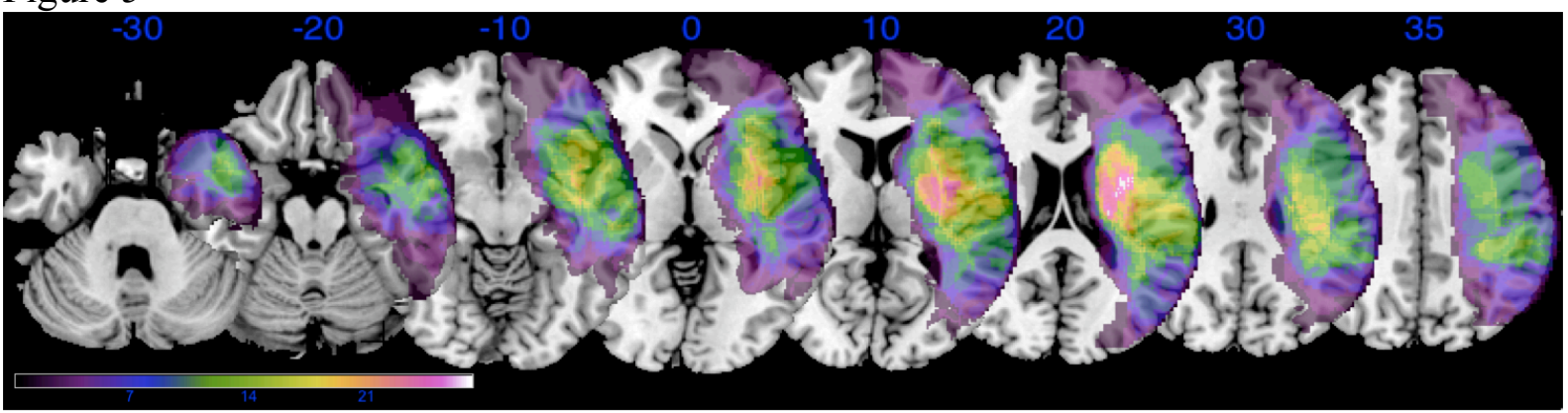




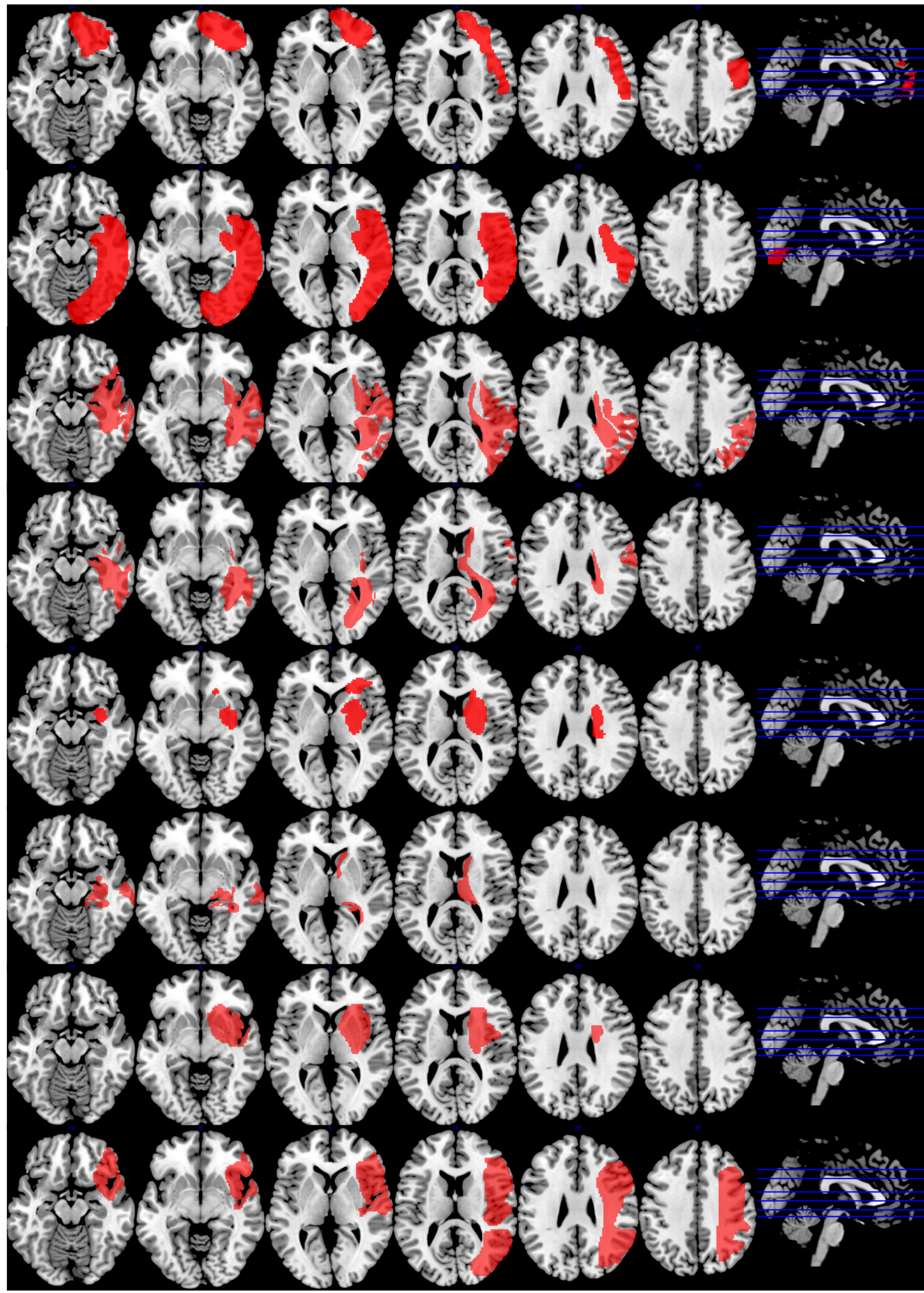


Figure S1A
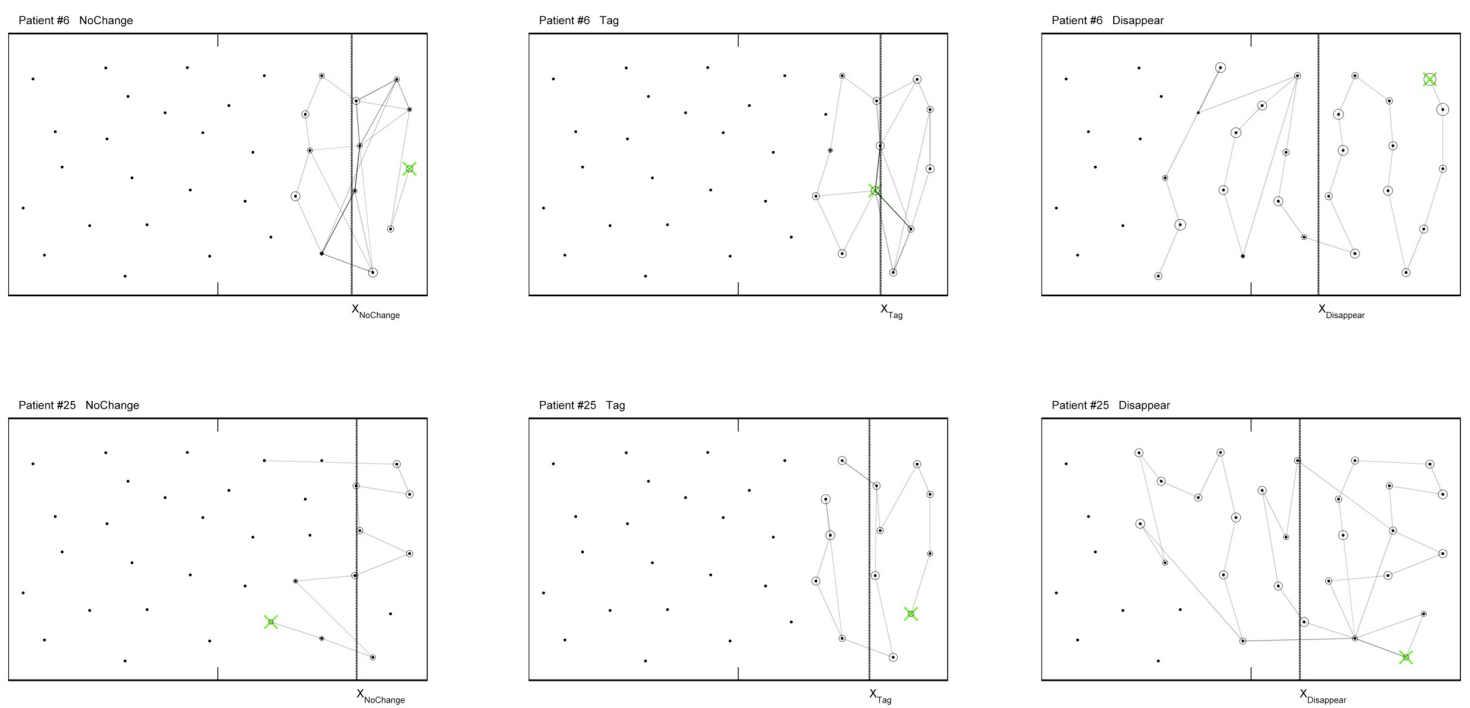

Figure S1B
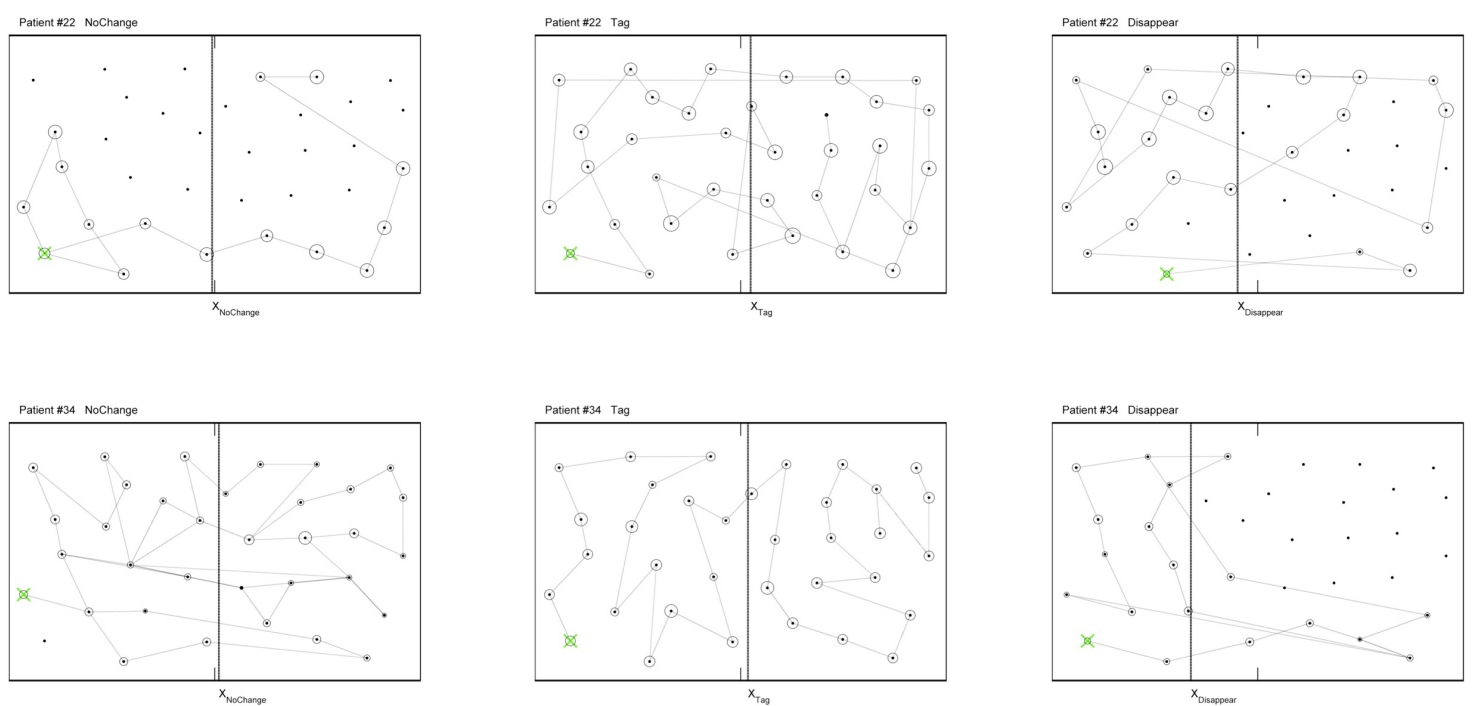
Figure S2A
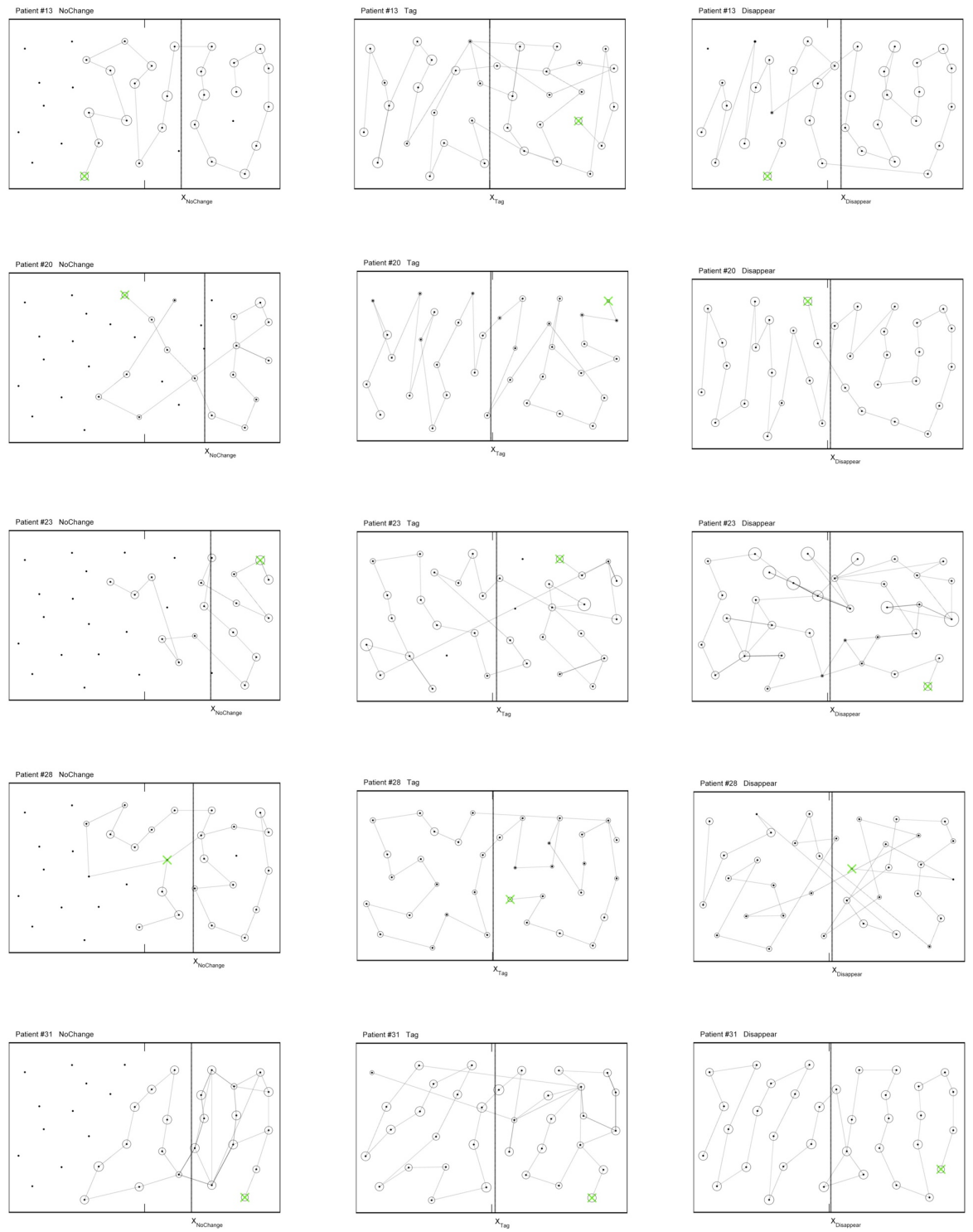
Figure S2B
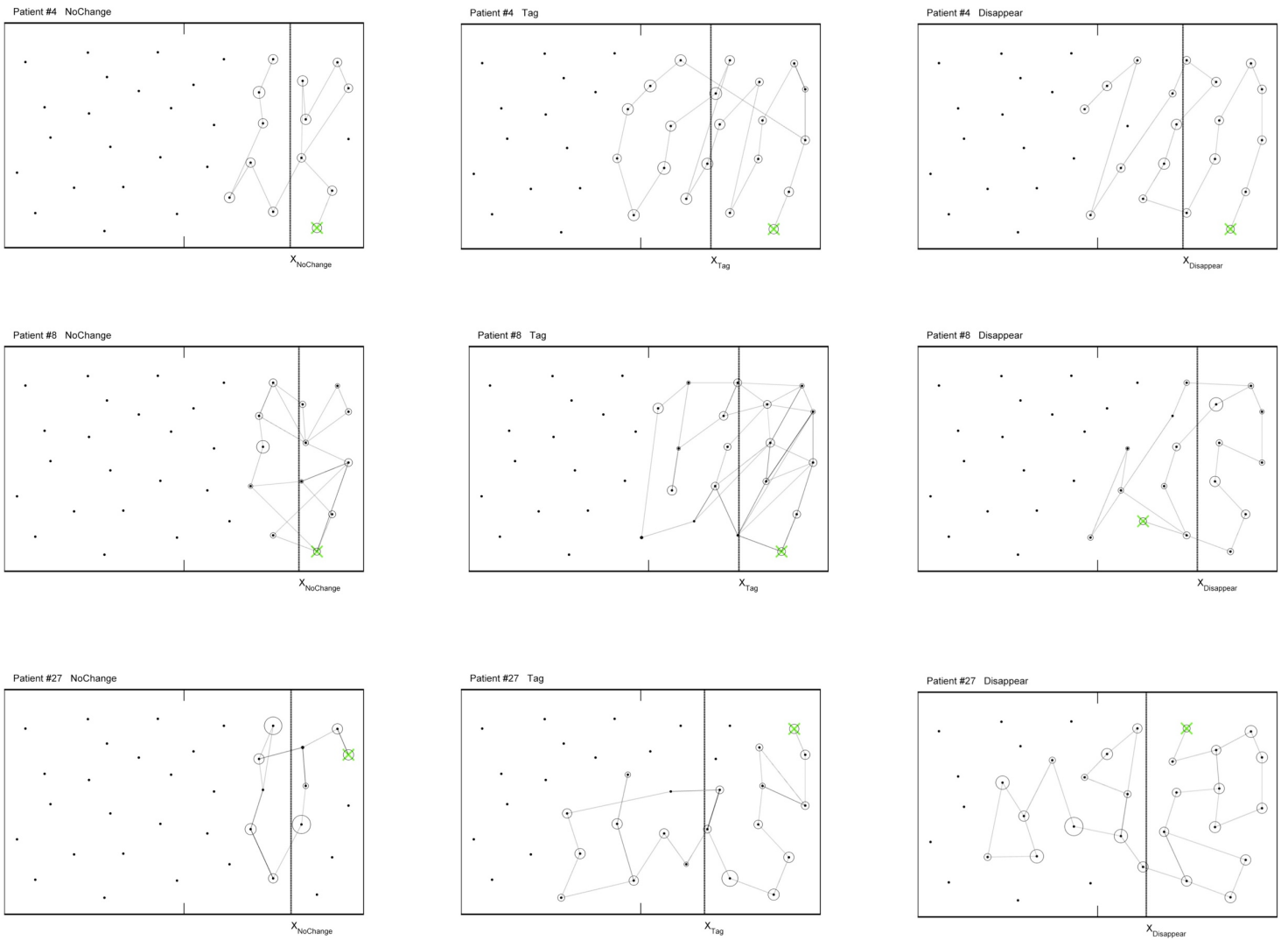
Figure S2C
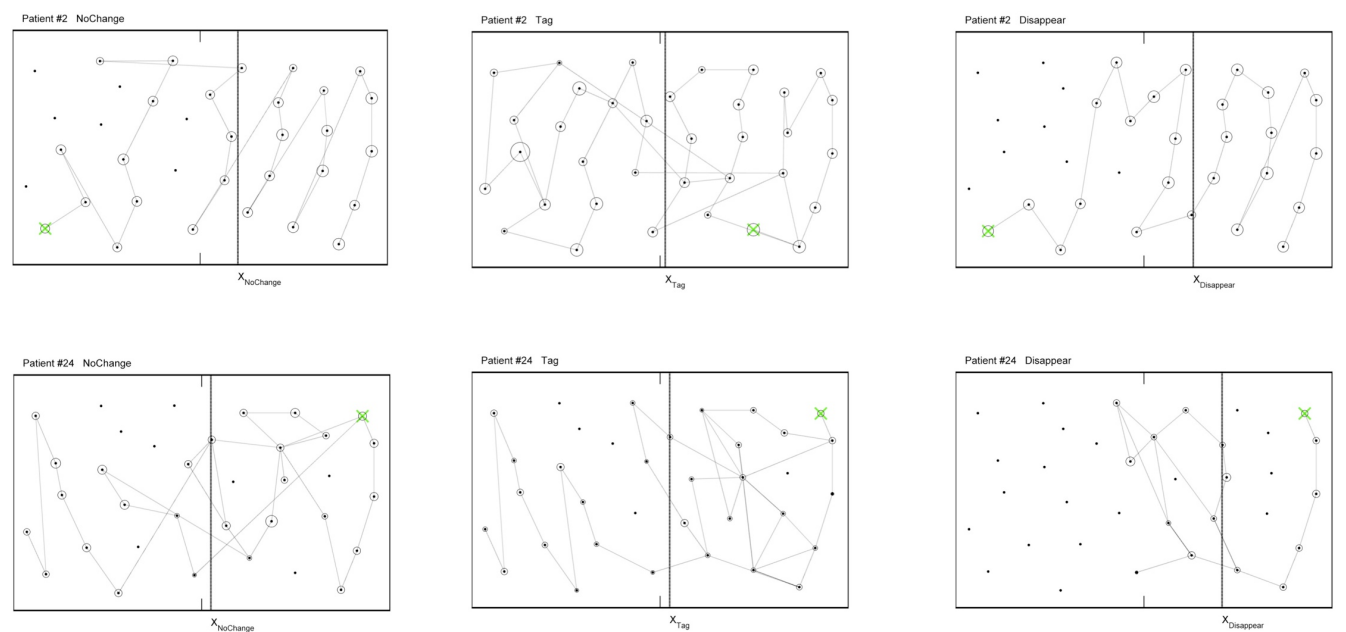
Figure S3A

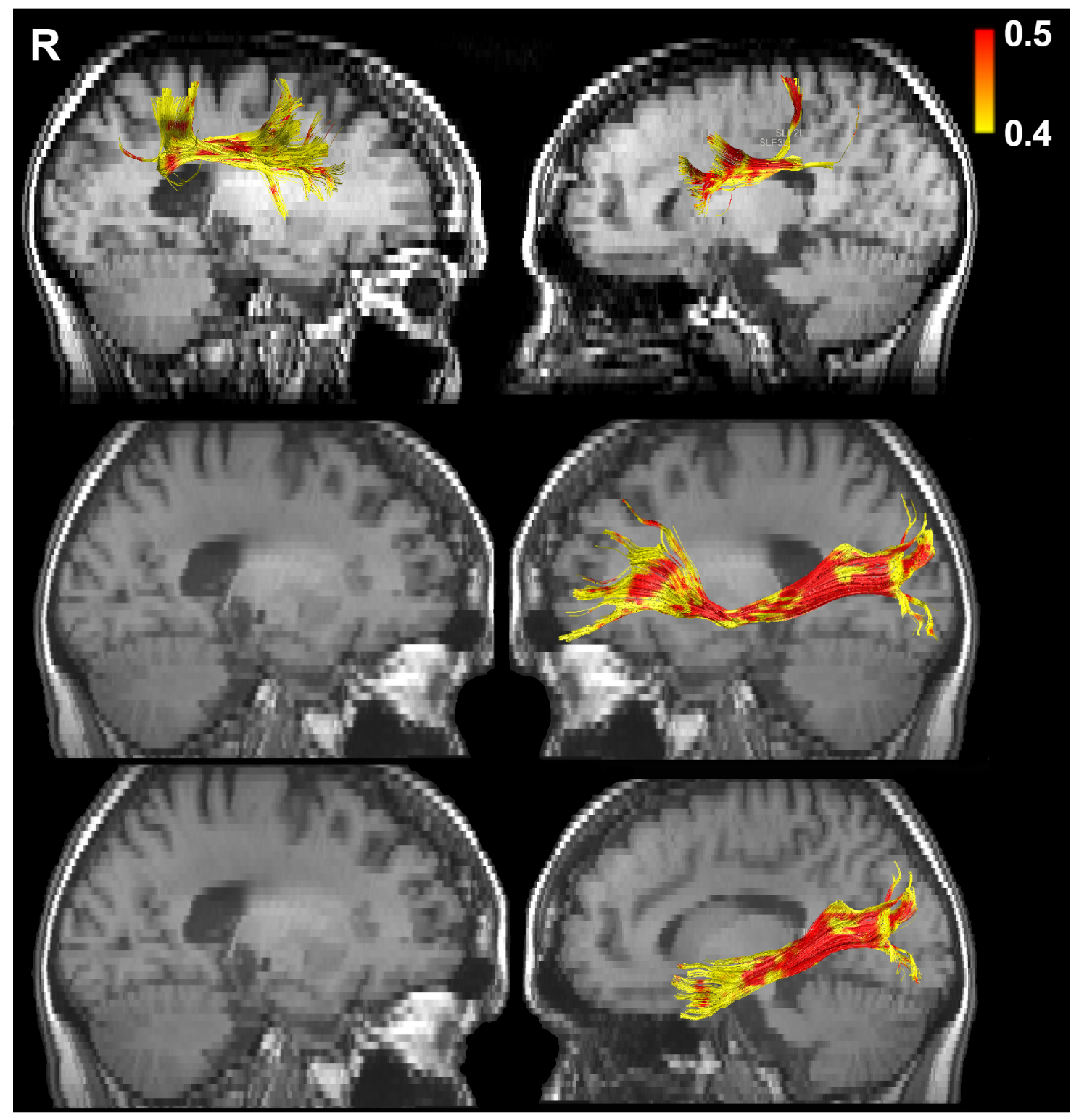


Figure S3B

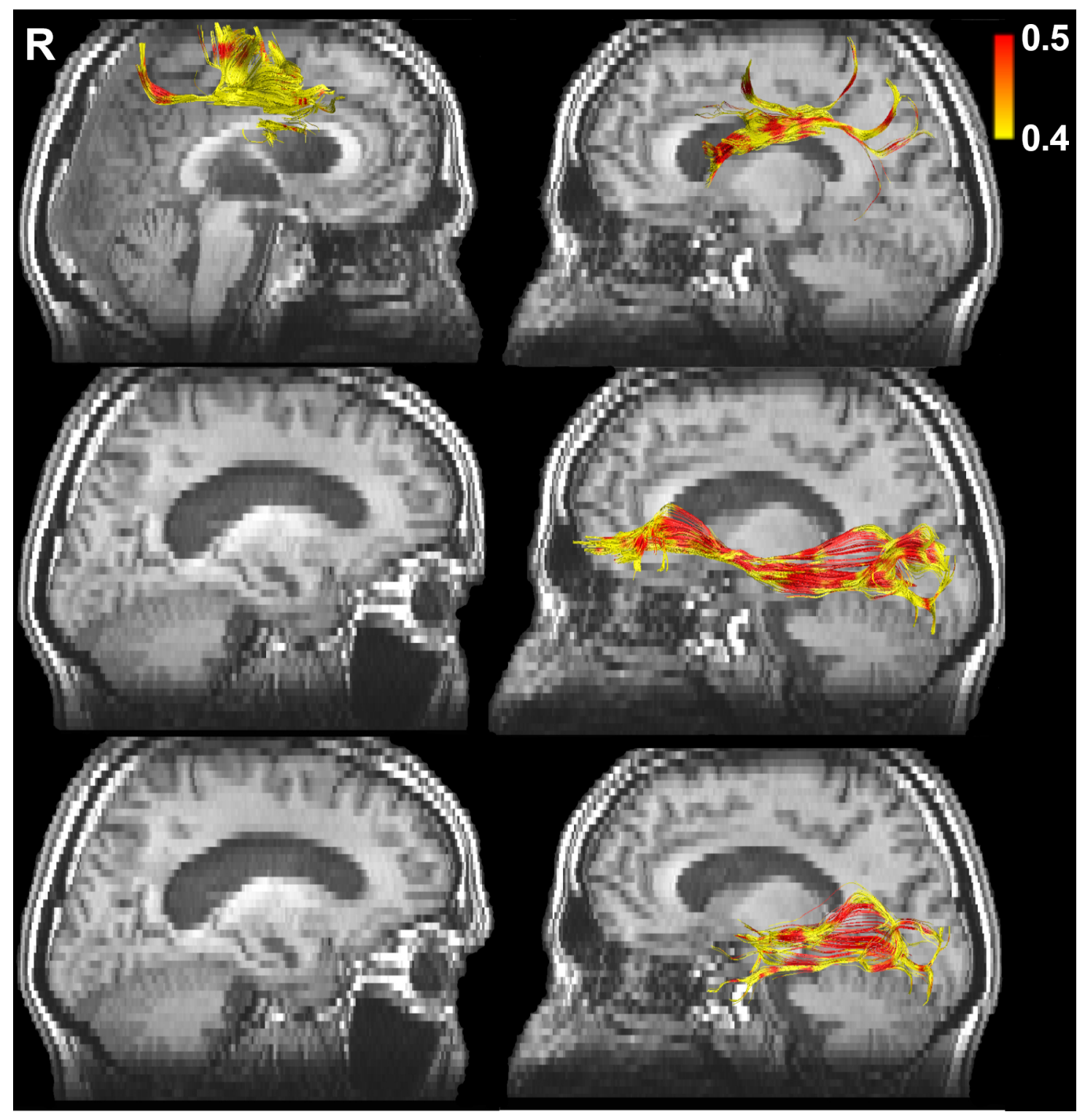


Figure S4
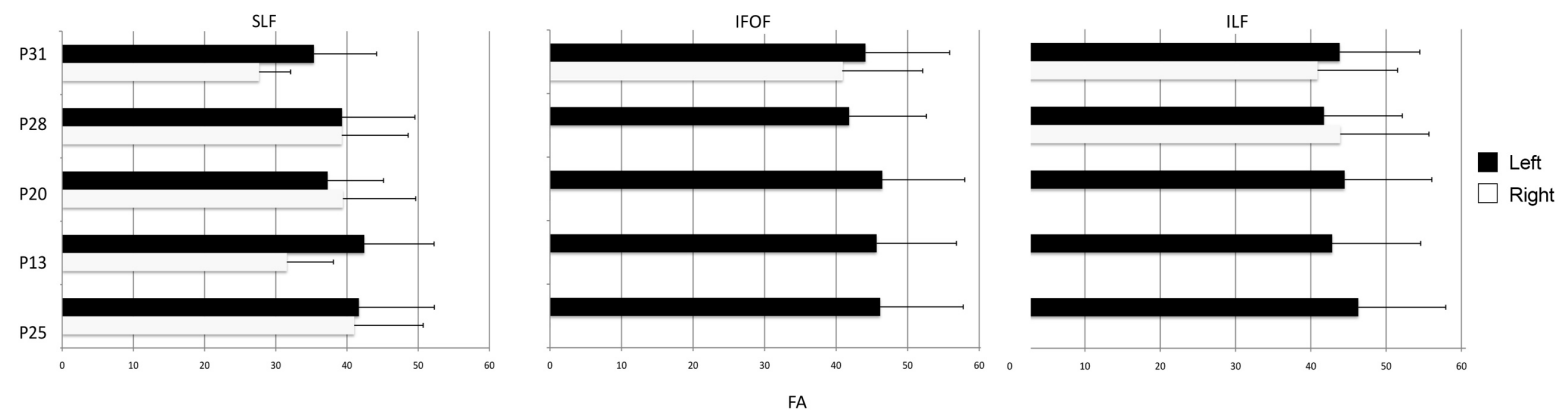